\title{
Large-scale integration of offshore wind into the Japanese power grid
}

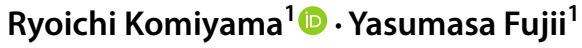

Received: 15 May 2020 / Accepted: 6 January 2021

(c) The Author(s) 2021, corrected publication 2021

\begin{abstract}
Offshore wind power attracts intensive attention for decarbonizing power supply in Japan, because Japan has $1600 \mathrm{GW}$ of offshore wind potential in contrast with $300 \mathrm{GW}$ of onshore wind. Offshore wind availability in Japan, however, is significantly constrained by seacoast geography where very deep ocean is close to its coastal line, and eventually, nearly $80 \%$ of offshore wind resource is found in an ocean depth deeper than $50 \mathrm{~m}$. Therefore, power system planning should consider both the location of available offshore wind resource and the constraint of power grid integration. This paper analyzes the impact of power grid integration of renewable resources including offshore wind power by considering the detailed location of offshore wind resource and the detailed topology of power grid. The study is performed by an optimal power generation mix model, highlighted by detailed spatial resolution derived from 383 nodes and 472 bulk power transmission lines with hourly temporal resolution through a year. The model identifies the optimal integration of power generation from variable renewables, including offshore wind, given those predetermined capacities. The results imply that, together with extensive solar PV integration, total $33 \mathrm{GW}$ of offshore wind, composed of $20 \mathrm{GW}$ of fixed foundation offshore wind and $13 \mathrm{GW}$ of floating offshore wind could contribute to achieve $50 \%$ of renewable penetration in the power supply of Japan, and that scale of offshore wind integration provides a technically feasible picture of large-scale renewable integration in the Japanese power sector.
\end{abstract}

Keywords Offshore wind power · Electric power grid · Optimization · Linear programming · Variable renewable energy $\cdot$ Power system operation

\begin{tabular}{|c|c|}
\hline Nomenclature & \\
\hline Endogenous variables & \\
\hline$A p_{i, d}$ & $\begin{array}{l}\text { Available capacity of } i \text {-th } \\
\text { power plant in day } d(\mathrm{GW})\end{array}$ \\
\hline$C h a_{j, d, t}$ & $\begin{array}{l}\text { Inflow of } j \text {-th power storage } \\
\text { facility in day } d \text {, time } t(\mathrm{GW})\end{array}$ \\
\hline$C S_{j}$ & $\begin{array}{l}\text { Cost of } j \text {-th power storage } \\
\text { facility (yen/year) }\end{array}$ \\
\hline$D i s_{j, d, t}$ & $\begin{array}{l}\text { Outflow of } j \text {-th power storage } \\
\text { facility in day } d \text {, time } t(\mathrm{GW})\end{array}$ \\
\hline $\operatorname{Dmax}_{i, d}$ & $\begin{array}{l}\text { Maximum output of } i \text {-type } \\
\text { power plant in day } d \text { and } \\
d+1(\mathrm{GW})\end{array}$ \\
\hline
\end{tabular}

Handled by Masa Sugiyama, University of Tokyo, Japan.

Ryoichi Komiyama

komiyama@n.t.u-tokyo.ac.jp

Department of Nuclear Engineering and Management, The University of Tokyo, 7-3-1 Hongo, Bunkyo-ku,

Tokyo 113-8656, Japan
$K_{i}$

$K S_{1 j}$

$K S_{2 j}$

$K T_{b}$

$M k_{i, m}$

$P_{i, d, t}$

$Q_{n}$

$S S_{j, d, t}$

Capacity of $i$-th power plant (GW)

Power capacity $(\mathrm{kW})$ of $j$-th electricity storage facility (GW)

Energy capacity $(\mathrm{kWh})$ of $j$ th electricity storage facility (GWh)

Power transmission capacity of branch $b(\mathrm{GW})$

Unavailable capacity of $i$-th power plant in $m$-th maintenance schedule (GW)

Electricity output of $i$-th type of power plants in day $d$, time $t(\mathrm{GW})$

Phase angle at bus $n$

Stored electricity of $j$-th power storage facility in day $d$, time $t(\mathrm{GWh})$ 


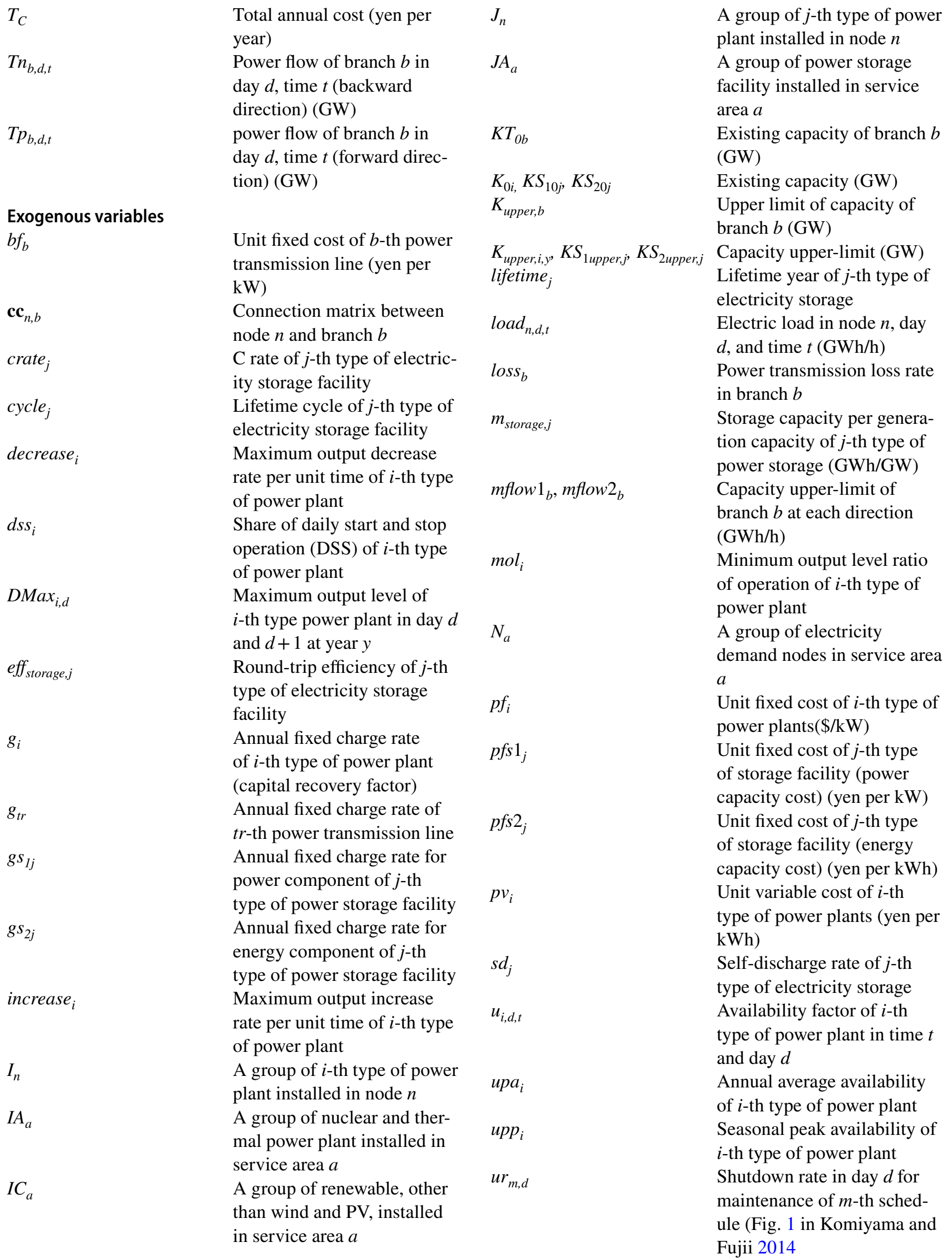




\begin{tabular}{|c|c|}
\hline$u s 1_{j, d}$ & $\begin{array}{l}\mathrm{kW} \text { availability factor of } j \text {-th } \\
\text { type of storage facility }\end{array}$ \\
\hline$u s 2_{j, d}$ & $\begin{array}{l}\mathrm{kWh} \text { availability factor of } \\
j \text {-th type of storage facility }\end{array}$ \\
\hline$x_{b}$ & $\begin{array}{l}\text { Reactance of power trans- } \\
\text { mission line } b\end{array}$ \\
\hline$\delta$ & Reserve margin $(=8 \%)$ \\
\hline \multicolumn{2}{|l|}{ Index } \\
\hline$i$ & $\begin{array}{l}\in\{0-61 \text {, Natural gas GCC, } \\
\text { 62-91: Oil fired, 92-100: } \\
\text { Natural gas fired, 101-148: } \\
\text { Coal fired, 149-163: } \\
\text { Nuclear, 164-207: Hydro, } \\
\text { 208-223: Geothermal, } \\
\text { 224-319: Biomass, 320-330: } \\
\text { Marine, 331-682: Onshore } \\
\text { Wind, 683-713: Offshore } \\
\text { Wind, 714-1065: Solar PV }\}\end{array}$ \\
\hline$j$ & $\begin{array}{l}\in\{0-26 \text { : Pumped, } 27-378: \\
\text { NAS battery, 379-730: Li- } \\
\text { ion battery }\}\end{array}$ \\
\hline$d$ & $\begin{array}{l}\in\{0,1,2, \ldots, D-1\} D: \\
\text { number of the day per year } \\
(D=365 \text { or } 366)\end{array}$ \\
\hline$t$ & $\begin{array}{l}\in\{0,1,2, \ldots, T-1\} T: \text { num- } \\
\text { ber of the time steps per day } \\
\left(T=24^{*} 6=144\right)\end{array}$ \\
\hline$n$ & $\begin{array}{l}\in\{0,1,2, \ldots, N-1\} N \text { : num- } \\
\text { ber of total buses }(N=352)\end{array}$ \\
\hline$b$ & $\begin{array}{l}\in\{0,1,2, \ldots, B-1\} B: \\
\text { Number of total branches } \\
(B=441)\end{array}$ \\
\hline
\end{tabular}

\section{Introduction}

Offshore wind power attracts intensive attention for decarbonizing future power supply in Japan, because Japan potentially holds $1600 \mathrm{GW}$ of offshore wind resource (technical resource) in comparison with $300 \mathrm{GW}$ of onshore wind as shown in Fig. 1, due to the very long coastal line in the world derived from the feature of national land area entirely surrounded by the ocean (MOE 2011). As of 2018, ongoing offshore wind power development projects in Japan, which are subject to environmental impact assessment, amount to $5.4 \mathrm{GW}$ in the ocean regions (METI/MLIT 2018). The study (JWPA 2017) shows the scenario that expects the expansion of offshore wind capacity in Japan to $37 \mathrm{GW}$ in 2050. Although solar PV has been the mainstream of renewable energy penetration in Japan, the political interest by the Japanese government has shifted from solar PV to offshore wind which might more contribute to replace thermal units and mitigate carbon emissions due to the higher capacity factor. The government has been politically eager to reduce the cost of offshore wind power generation, and the feedin-tariff (FIT) for offshore wind is institutionally arranged as the most profitable for the power operators. The FIT for offshore wind in 2019, both fixed foundation and floating offshore wind powers, shows 36 yen per kWh (METI 2019; METI 2020), equal to 33 cents per $\mathrm{kWh}$, being double of that in PV and onshore wind. In addition, in November 2018, the Japanese Diet has approved a new bill for offshore wind promotion, called as the bill on promotion of territorial waters utilization for offshore renewable energy facilities (METI 2018a). As denoted in the bill, national and local governments collaboratively specify appropriate lease zones for offshore wind power, and the developers lodge competitive
Fig. 1 Resource potential of renewable energy in Japan, compiled from (MOE 2011)

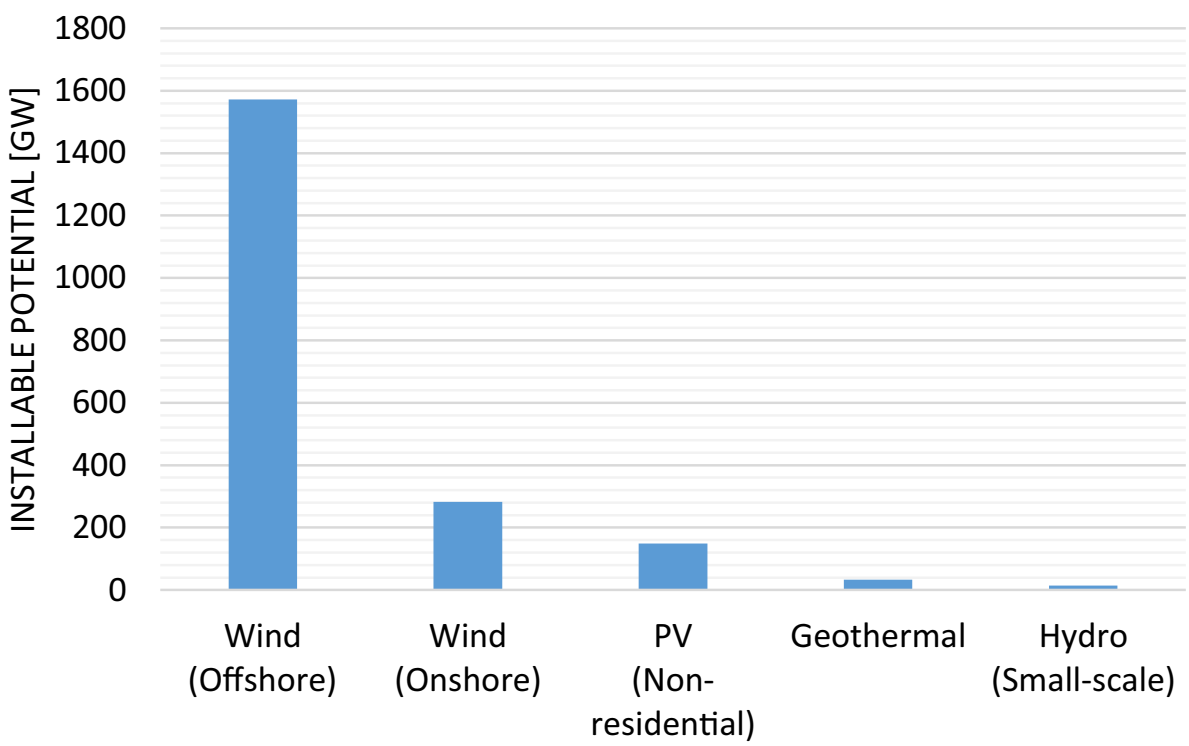


bids for the use of the zones with proposing a price of FIT and the development plan. Finally, the winners have the right to occupy and utilize the leased zone for a maximum of 30 years and receive a FIT for 20 years.

Although Japan has abundant offshore wind resources, economical and technical viability of offshore wind grid integration is significantly constrained by its geographical characteristics. Japan has a unique geographical structure of very steep and deep seawaters close to its coastal line. Only a few areas are near shallow water in Japan. Therefore, nearly $80 \%$ of offshore wind resource is located in an ocean depth deeper than $50 \mathrm{~m}$, as illustrated in Fig. 2 which is made using the data shown in the literature (NEDO 2009). European region, on the other hand, which progressively promotes the installation of offshore wind, holds large deployable sites in shallow ocean suitable for a development of fixed foundation offshore wind. Due to the specific coastal geographical structure in Japan, hence, floating offshore wind, which is still under development for full-fledge commercialization, is a candidate to promote wind energy in the national power generation mix. In addition, the Japanese power grid structure is not inherently suitable for integrating renewable energy. For example, Tohoku region, where enough resource of fixed foundation offshore wind is available, has severe grid capacity constraints to integrate the offshore wind output, because Tohoku is the place which does not encompass a sufficient electricity demand equal to its abundant offshore wind resource. Therefore, for connecting large-scale offshore wind, Japan has technical challenges in the power grid to address geographical disparity between the place where electricity is generated and the place where electricity is consumed, for example, by reinforcing power transmission lines. The limited capacity of power grid is estimated to constrain the grid access of onshore wind as well in Japan (Mizuno 2014). To assess the integration of offshore wind power into a power grid, thus, elaborate consideration is required for a topology of power grid as well as a location of

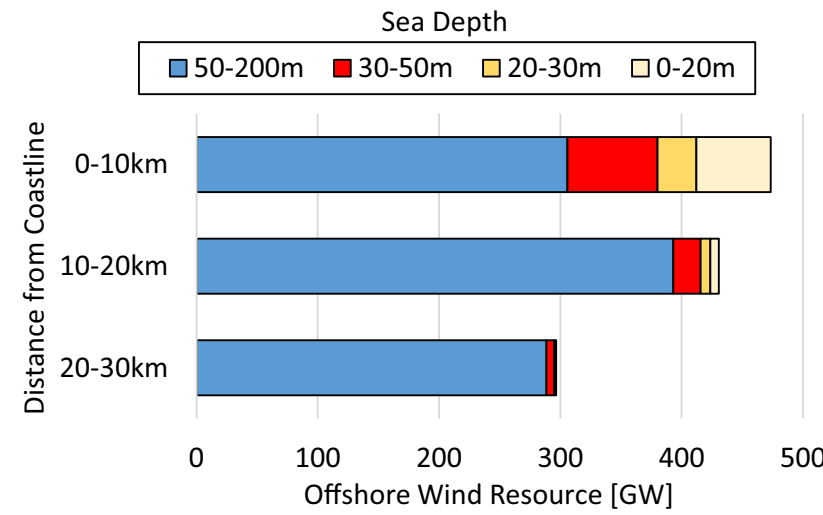

Fig. 2 Resource potential of offshore wind power by sea depth and by distance from coastline, compiled from (NEDO 2009) offshore wind resource. In addition, a large-scale renewable integration causes a drop of wholesale power price, because VRE variable cost is almost zero and it substitutes thermal power units which requires fuel cost for incrementing power output through a merit-order dispatch in wholesale power market. As actually observed in a part of Japan, renewable integration in power system has enormously pushed down the level of wholesale electricity price. In Kyushu electric power company, wholesale price is observed to stick to zero when solar PV generates in daytime. Nowadays, political measures are considered to be necessary to resolve the negative impact of collapsing wholesale price on power supply investment.

Against those backgrounds, this paper develops an optimal power generation mix model which takes into consideration a detailed topology of the Japanese power grid and analyzes the power grid integration of renewable resources in 2030 including fixed foundation and floating offshore wind powers on the basis of official assessment for offshore wind resources (MOE 2015).

Until now, in a power grid study, the feasibility of renewable energy integration is evaluated using a computational simulation model. Renewable integration is analyzed, focusing on the effect of wind power on unit commitment dispatch through $36 \mathrm{~h}$ (Tuohy et al. 2009) and in isolated power system of Gran Canaria by considering demand response (Dietrich et al. 2012), high renewable penetration in Australia by hourly merit order dispatch (Elliston et al. 2012), cost-minimized combinations of various renewable resources with electrochemical storage (Budischak et al. 2013), a stochastic analysis for the grid integration of wind and solar with a Monte Carlo simulation (Hart and Jacobson 2011), and the potential for a fully renewable power generation mix at each half-hourly interval (Becker et al. 2014). Multi-nodal power system analysis has been conducted as well, highlighting the penetration of renewables with regional linear optimization model of European power system considering power transmission network (Schaber et al. 2012), the operational impact of given energy penetration of wind and PV considering US inter-state transmission constraint (NREL 2014), the locational impact of renewables on power transmission congestion in a IEEE 30-bus test grid (Hitaj 2015), a unit commitment problem aiming to minimize the system cost under IEEE test power system (Marzooghi et al. 2016; Riaz et al. 2019), a long-term scenario development of a U.S. power grid integrating renewable energy up to $80 \%$ of 2050 annual electricity by considering 134 balancing areas (Mai et al. 2014), an evaluation of longterm decarbonization scenario for the Chinese power system by power grid expansion model covering 31 load areas ( $\mathrm{He}$ et al. 2016) and a scenario generation framework capturing inter-spatial dependencies between loads and wind output 
in various locations under a modified IEEE 118-bus system (Sun et al. 2018).

The above existing literatures coping with a power grid analysis, however, does not evaluate the detailed integration effect of fixed foundation and floating offshore wind powers by considering a detailed structure of power grid topology and a detailed temporal resolution such as hourly resolution in $8760 \mathrm{~h}$ per year. Few studies so far develop the model including several hundred nodes and power lines in an hourly temporal resolution through a year, and evaluate the power grid integration of VRE including offshore wind.

This manuscript analyzes alternative power supply scenarios focusing on offshore wind power with an optimal power generation mix model, and evaluate how much renewable power can be economically integrated by considering energy storage and its output curtailment and how much non-fossil power generation can be economically integrated as much as possible in national power supply. The model is characterized by considering the power grid topology composed of 383 nodes and 472 high-voltage power transmission lines in Japan with an hourly resolution in $8760 \mathrm{~h}$ per year. This paper upgrades the model, which the authors previously developed from scratch and considers a grid topology at 135 buses and 166 power lines
(Komiyama and Fujii 2017), to entirely handle all of the high-voltage power grid at 383 buses and 441 bulk power transmission lines for newly considering offshore wind integration. Therefore, the originality of this study is to assess the optimal VRE integration including offshore wind into a power grid by considering the constraint of whole bulk power transmission line and to show the optimal picture of VRE integration in a higher temporal resolution. Based on the model, this paper evaluates the impact of extensive renewable integration on $\mathrm{CO}_{2}$ emissions of the power system.

\section{Offshore wind power potential}

Concerning onshore wind power potential in Japan as shown in Fig. 3, desirable locations, which are colored in green, yellow and red, can be observed around Hokkaido and Tohoku areas, while offshore wind power potential as depicted in Fig. 4 are spread nationwide covering Kanto, Chubu and Kyushu regions together with Hokkaido and Tohoku. Onshore desirable locations are concentrated heavily on Hokkaido and Tohoku regions, together dominating $80 \%$ of the national onshore wind potential. As described, offshore wind
Fig. 3 Average annual onshore wind speed over 20 years across the country, compiled from (MOE 2013)

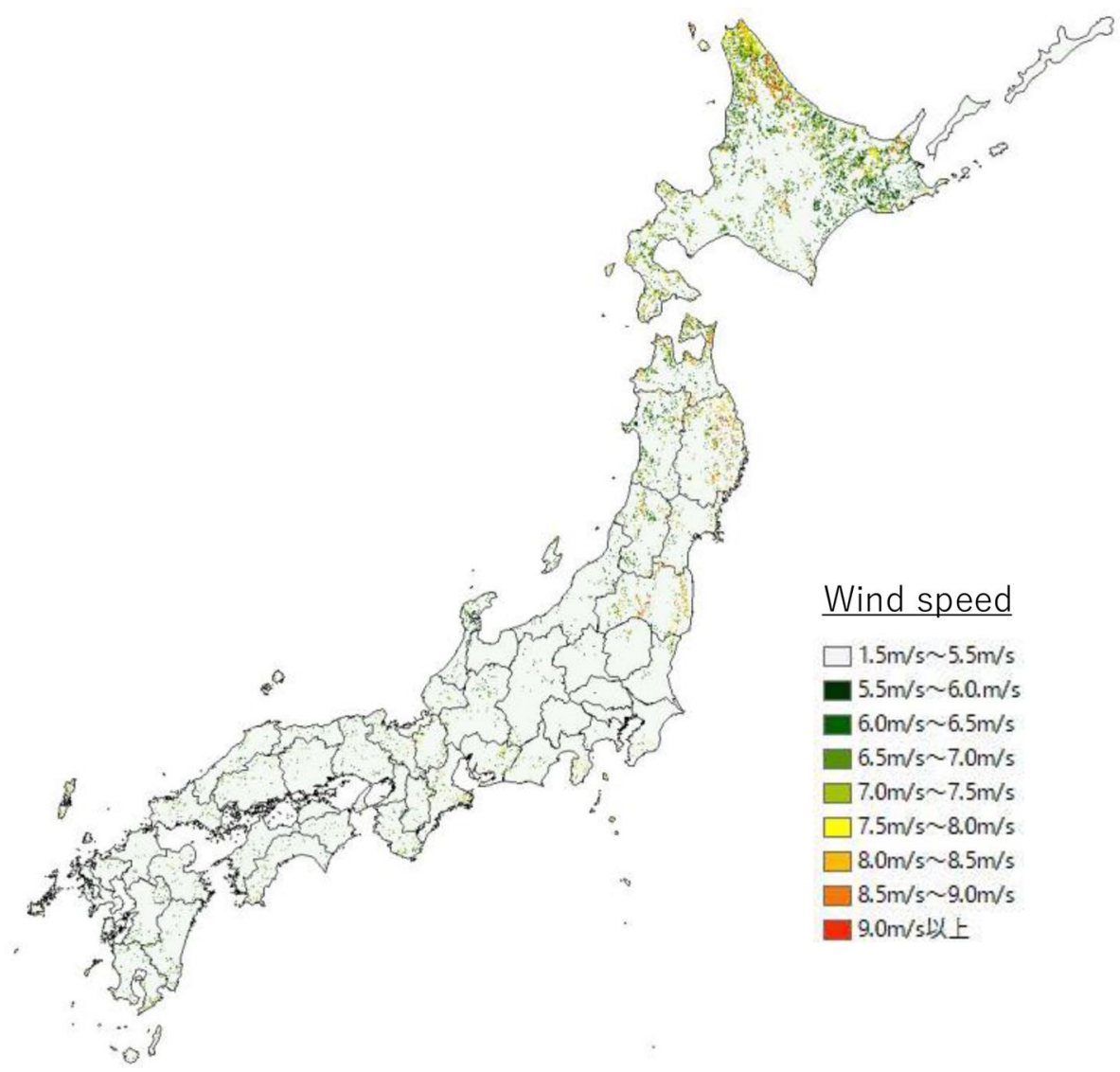


Fig. 4 Average annual offshore wind speed over 20 years across the country, compiled from (MOE 2013)

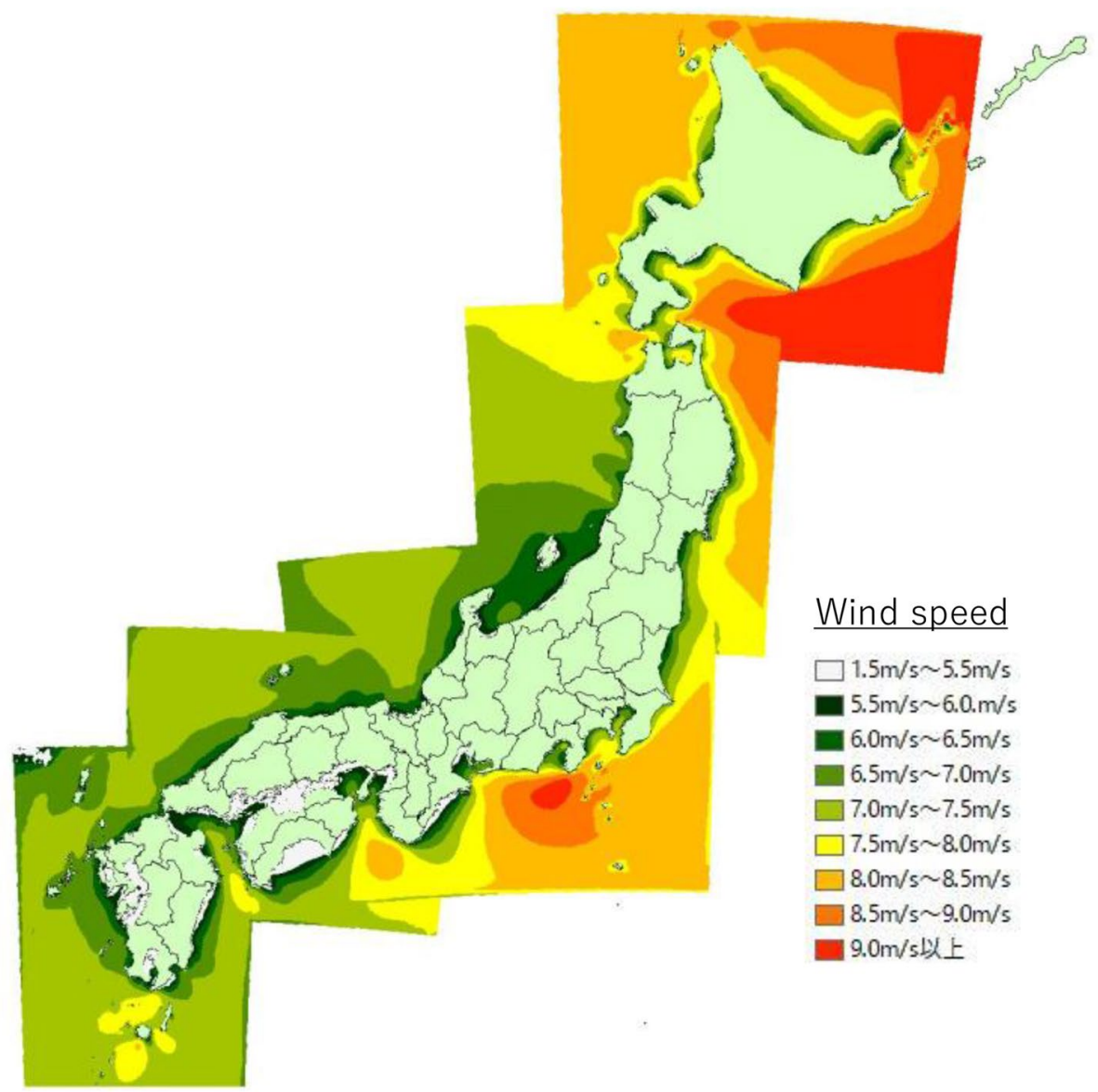

power attracts an interest a lot in Japan, because Japan has a long coastal line and $1600 \mathrm{GW}$ of offshore wind potential which is evenly distributed nationwide and can potentially increase its integration into the national power system.

A study (MOE 2015) elaborately estimates the potential capacity of offshore wind power generation by considering the geographical proximity between the location of offshore wind resource and the location of high-voltage substation in a power grid. In the estimation, the study assesses the conditions of offshore wind speed throughout the country based on the numerical weather simulations over the past 20 years. Furthermore, the study specifies grid access points of offshore wind in existing high-voltage substations which is explicitly and consistently included in the model developed here. Based on those considerations, as shown in Table 1, the study assesses the integration potential of offshore wind power into the grid for each electricity service area. The study focuses on the offshore area with wind speed more than $7.0 \mathrm{~m} / \mathrm{s}$ and with sea depth less than $50 \mathrm{~m}$ for fixedfoundation offshore wind. As far as distance from coastline, fixed-foundation offshore is assumed from 10 to $40 \mathrm{~km}$, while floating offshore is from 40 to $80 \mathrm{~km}$. Furthermore, the study assumes that the available sites of offshore wind installation are located less than $100 \mathrm{~km}$ from high-voltage
Table 1 Resource potential of offshore wind power generation in Japan, considering wind speed, distance from coastline, sea depth and proximity to the power grid

\begin{tabular}{lll}
\hline Service area & Fixed foundation $(\mathrm{GW})$ & Floating $(\mathrm{GW})$ \\
\hline Hokkaido & 0.68 & 0 \\
Tohoku & 9.91 & 9.02 \\
Tokyo & 7.52 & 15.26 \\
Hokuriku & - & - \\
Chubu & 5.88 & 5.58 \\
Kansai & 0 & 1.01 \\
Chugoku & - & - \\
Shikoku & 0.48 & 3.04 \\
Kyushu & 0.44 & 1.68 \\
Okinawa & - & - \\
Total & 24.91 & 35.59 \\
\hline
\end{tabular}

Source. Ministry of Environment, Japan (MOE 2015)

substation. Through those assumptions, the study explicitly considers the geographical proximity between an offshore wind potential and a power grid. As a result, the study evaluates $25 \mathrm{GW}$ of fixed foundation offshore wind and $36 \mathrm{GW}$ of floating offshore wind in Table 1. Based on the study (MOE 
2015) where offshore wind potential is estimated by considering wind speed, grid topology, and the distance from coast and sea depth, this paper scrutinizes the estimation and assumes that $20 \mathrm{GW}$ of fixed foundation offshore wind and $13 \mathrm{GW}$ of floating offshore wind could be potentially deployed in the national power grid. Because of the differences of the grid topology are observed between the study (MOE 2015) and this paper, the connectable capacity of offshore wind power in this study is slightly different from the study (MOE 2015).

\section{Optimal power generation mix model of Japan (OPGM model)}

In this paper, an electric power system integrated with largescale offshore wind is analyzed together with other variable renewable energies (VREs) by developing an optimal power generation mix (OPGM) model covering entire nationwide power grid. The model is formulated with a linear programming approach. The minimization of total power system cost enables us to specify the best mix of a power system through $8760 \mathrm{~h}$ in a single year. For achieving higher VRE penetration, strategic energy policy is imperative for transforming a power grid (IEA 2014), and the model developed here is suitable for a power system planning to support such a policy formulation. An optimal power generation mix model here is basically an optimal power system model which economically dispatches electricity from individual power generator for power demand, although the capacity of rechargeable battery is endogenously determined through the cost optimization. Thus, the model mainly determines the economically optimal power supply from each generator for each hour of the year, and not calculates the power capacity expansion other than rechargeable battery.

Compared with the authors' previous studies (Komiyama and Fujii 2014, 2017), total 31 offshore nodes are explicitly embedded for considering the integration of offshore wind power. Based on the information of (IEEJ 2004), the topology of power transmission lines is explicitly considered in the model as shown in Fig. 5. Concerning power generators, the model considers nuclear, hydro, geothermal, coal-fired, LNG-fired (steam turbine, combined cycle), oil-fired, solar $\mathrm{PV}$, onshore wind, offshore wind and energy storage. As energy storage technology, the model incorporates the possible deployment of sodium-sulfur (NAS) battery and Liion battery as well as pumped-storage hydro-power. Active power flow of the grid is modeled through a direct current (DC) method. This paper, however, does not consider thermal power plants equipped with CCS (carbon capture and storage) due to the limitation of computational capability, and the consideration of CCS is positioned as a future research topic. In addition, in this model, advanced power

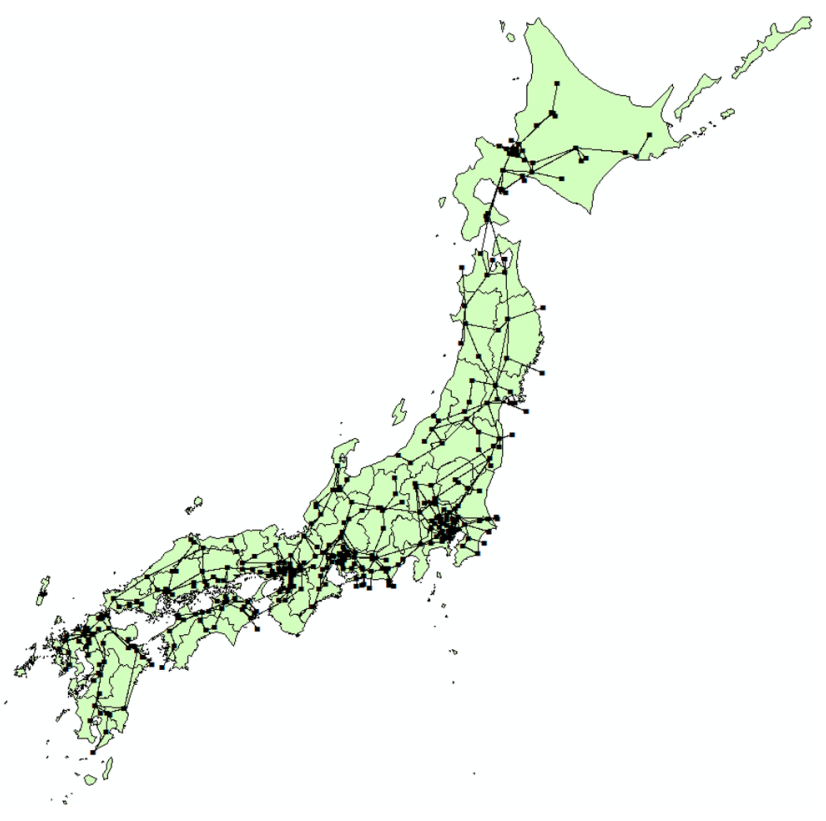

Fig. 5 Locational distribution of 383 buses and 472 high-voltage power transmission lines in Japan. 31 offshore nodes are explicitly considered

technology such as hydrogen power generator is not considered as well, and it should be kept in mind that the total power system cost could be overestimated if the technologies have economical competitiveness in the power system.

In the model, an annual calendar year is described by 8760 temporal segments ( $=24 \mathrm{~h}$ per day $\times 365$ days per year) and it allows us to consider a seasonal VRE output variation. Exogenous variables such as cost and technical assumptions are based on Komiyama and Fujii (2017). Regarding power demand data, this paper adopts electricity load curves which are all downloadable from the websites of utility companies, although demand response, observed a lot as demonstration projects in Japan, is not considered. If demand response (DR) is considered in the model, DR could serve as a role to reduce the dependence of balancing technology or operation such as the curtailment of renewable power output and rechargeable battery installation because DR could adjust power demand to power supply in each time. In this model, PV and onshore wind variabilities in each node are assumed through the authors' existing literatures (Komiyama and Fujii 2014) using official meteorological database (AMeDAS) (JMA 2007). Offshore wind power variabilities are estimated by meteorological database. Those different variabilities of solar $\mathrm{PV}$, onshore and offshore winds are integrated in the power grid model, and consequently, the impact through the leveling effect of VRE variabilities on a power system is explicitly reflected in this study.

This study analyzes the possibility of large-scale renewable integration including offshore wind in 2030, and the 
capacity of nuclear and thermal power generation is fixed at the capacity supposed in 2030 . The capacity of nuclear, thermal and renewable power generation is assumed as given variables according to electricity supply plans of each service area in 2030. This paper does scenario analysis on the given capacities of renewable as described later. In addition, the capacities of rechargeable batteries are endogenously calculated through the optimization, and the capacities of other plants are fixed on the basis of electricity supply plan (OCCTO 2015) and governmental long-term energy outlook (METI 2015) as shown in Fig. 6. Regarding nuclear power supply, this paper assumes almost the same fraction of nuclear power generation as that of the governmental outlook in 2030 (METI 2015) and sets the nuclear fraction as $21 \%$ of total electricity supply.

In this study, based on database (Renewables.ninja 2019), the yearly profiles of offshore wind output in an hourly interval are estimated in 31 offshore nodes in the model. As a result, annual average capacity factor of offshore wind achieves 37\% which is well above that of onshore wind, typically $20 \%$ in Japan. Figure 7 illustrates the output profile of offshore wind, for example, in January in all 31 offshore nodes of the model and implies that the trend of offshore wind power output has a long-term cycle such as a daily or weekly cycle. In addition, according to Fig. 8 illustrating average output profile of offshore wind through a year in Japan, the offshore wind output shows a seasonal cycle as well because its intensity tends to increase around winter season and to decline around summer season. Therefore, if offshore wind holds a large fraction in a power grid for the future, solving a daily, weekly or seasonal imbalance of offshore wind output will become a key agenda in a power system.

The basic structure of mathematical formulation of the model, together with the assumptions of technical parameters, is according to (Komiyama and Fujii 2014, 2017). As technical measures for the output variation of VRE, the model take into consideration typical multiple treatments, namely, electricity storage, output control of dispatchable generators, output curtailment of VRE and power exchange through power transmission lines, although demand response is out of consideration.

\section{Objective function}

Objective function corresponds to an annual total cost in a specific year. Capacity of power transmission lines is basically given, and exogenous variables concerning cost and technical specification are derived from Komiyama and Fujii (2017):
Fig.6 Locational distribution of nuclear, thermal and renewable energy in Japan

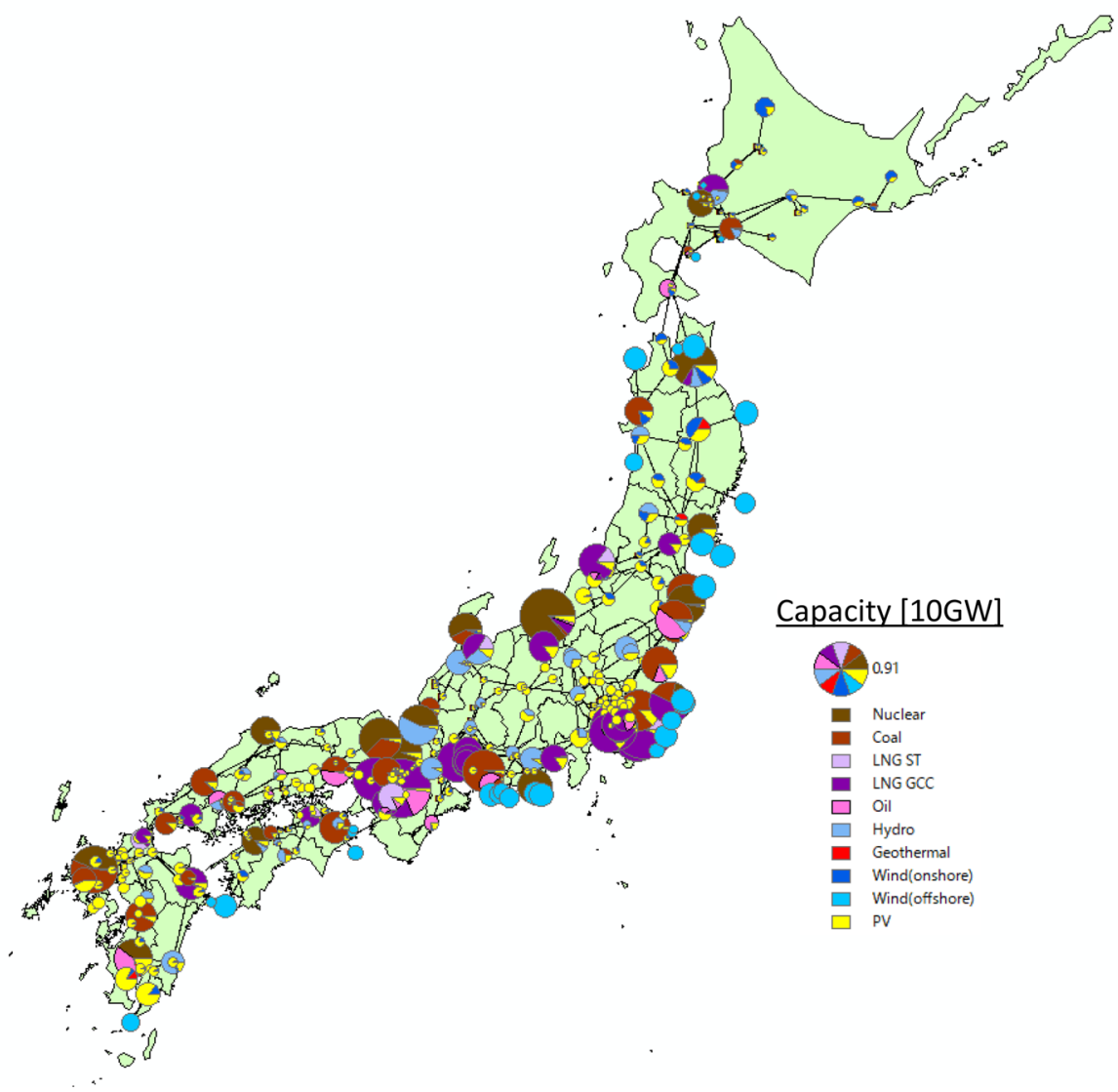




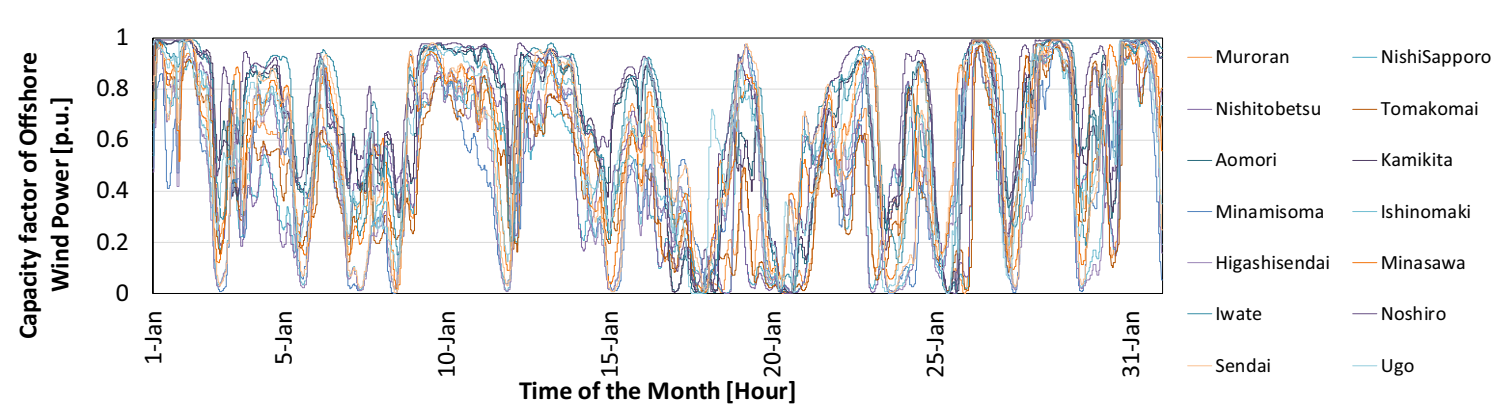

(a) Offshore wind outputs in 14 nodes (Hokkaido, Tohoku)

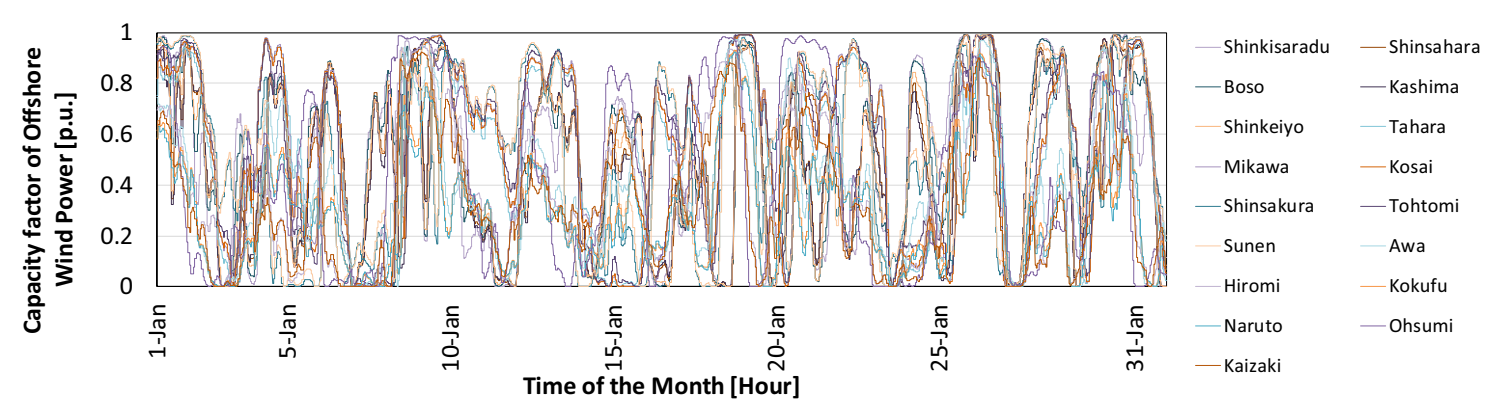

(b) Offshore wind outputs in 17 nodes (Kanto, Chubu, Shikoku, Kyushu)

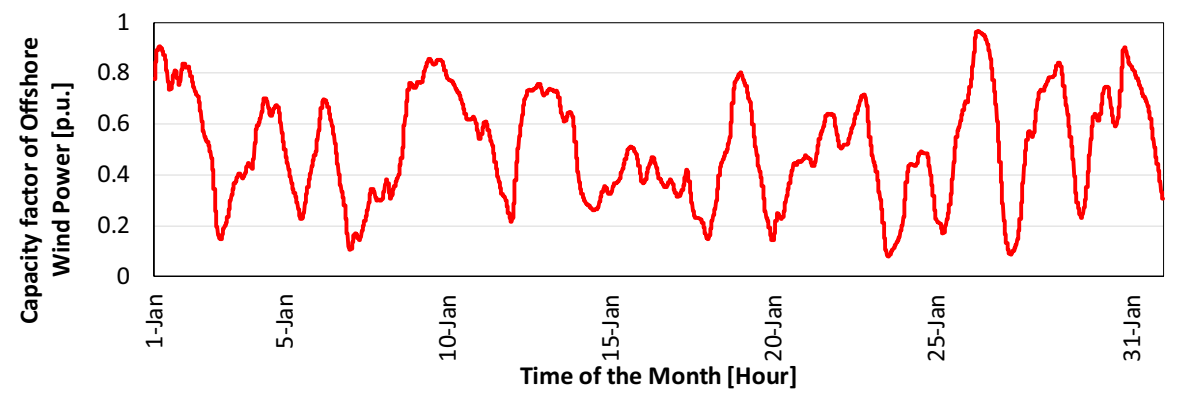

-Average

(c) Average output

Fig. 7 Offshore wind output profile in January on an hourly resolution in 31 offshore nodes in Japan and the average output profile, compiled from Renewables.ninja (2019)

$$
\min . T C=\sum_{i=0}^{499}\left(g_{i} \times p f_{i} \times K_{i}+\frac{1}{6} \sum_{d=0}^{D-1} \sum_{t=0}^{T-1} p v_{i} \times P_{i, d, t}\right)
$$

$+\sum_{j=0}^{244} C S_{j}+\sum_{b=0}^{B-1} g_{t r} \times b f_{b} \times K T_{b}$

$$
C S_{j}=\left(g s 1_{j} \times p f s 1_{j} \times K S 1_{j}\right)+\left(g s 2_{j} \times p f s 2_{j} \times K S 2_{j}\right) .
$$

Following descriptions are about the constraints in OPGM model.

\section{Power demand and supply balances}

Following constraints describe a balance equation between supply and demand. Equation (4) shows nodal electric power 


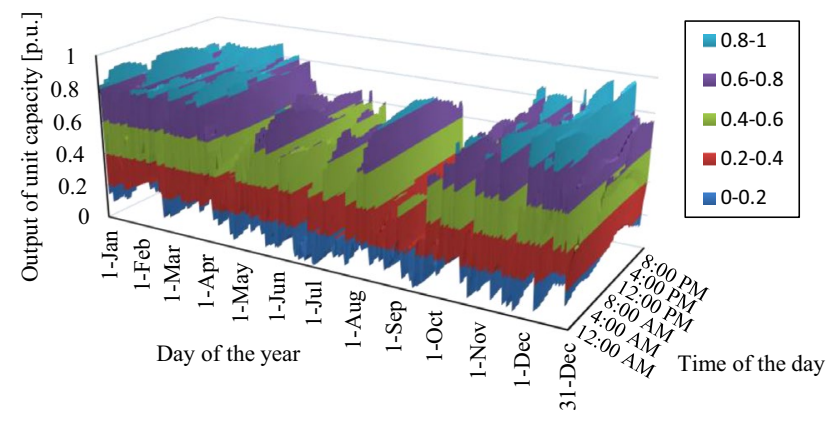

Fig.8 Average output profile of offshore wind on an hourly temporal resolution through a year in Japan, compiled from Renewables.ninja (2019)

flows and Eq. (5) depicts transmission losses of nodal power flows:

\section{Available capacity constraints of power supply technologies}

Equation (9) describes the upper-limit constraint of electric power output in nuclear and thermal power plants, and Eq. (10) shows that of other power plants. Concerning PV and wind outputs, this paper sets the outputs of unit capacity $u_{i, d, t}$ in Eq. (10), that is, yearly and hourly profiles of onshore wind, offshore wind and PV outputs using meteorological database (Renewables.ninja 2019; JMA 2007). As far as offhsore wind, the output variability as shown in Figs. 7 and 8 is explicitly considered:

$P_{i, d, t} \leq A p_{i, d}$

$P_{i, d, t} \leq u_{i, d, t} \times K_{i}$

$\sum_{i \in I_{n}} P_{i, d, t}+\sum_{j \in J_{n}}\left(D i s_{j, d, t}-C h a_{j, d, t}\right)+\sum_{b=0}^{B-1} \mathbf{c c}_{n, b}\left(T p_{b, d, t}-T n_{b, d, t}\right)-\operatorname{Loss}_{n, d, t}=\operatorname{load}_{n, d, t}$,

$T p_{b, d, t}-T n_{b, d, t}=\sum_{n}\left(\mathbf{c c}_{n, b} \cdot \frac{Q_{n, d, t}}{x_{b}}\right)$,

$\operatorname{Loss}_{n, d, t}=\frac{1}{2} \sum_{b=0}^{B-1}\left|\mathbf{c c}_{n, b}\right| \cdot \operatorname{loss}_{b}\left(T p_{b, d, t}+T n_{b, d, t}\right)$.

\section{Available capacity of power generation plants}

Electric power stations are occasionally shutdown for the maintenance to continue a stable electricity supply. Following equations determine active and inactive capacity of electric power station. More detailed explanations are available in Komiyama and Fujii $(2014,2017)$ :

$$
\begin{aligned}
& A p_{i, d}+\sum_{m=0}^{3}\left(u r_{m, d} \cdot M k_{m, i}\right)=K_{i}, \\
& \sum_{m=0}^{3}\left(u r_{m, d} \cdot M k_{m, i}\right) \geq\left(1-u p p_{i}\right) K_{i}, \\
& \frac{1}{D} \sum_{m=0}^{3} \sum_{d=0}^{D-1}\left(u r_{m, d} \cdot M k_{m, i}\right)=\left(1-u p a_{i}\right) K_{i} .
\end{aligned}
$$

$C h a_{j, d, t}+D i s_{j, d, t} \leq u s 1_{j, d} \times K S 1_{j}$

$S S_{j, d, t} \leq u s 2_{j, d} \times K S 2_{j}$

Constraints on upper and lower installable capacity

$K_{0 i} \leq K_{i} \leq K_{\text {upper }, i}$

$K S 1_{0 j} \leq K S 1_{j} \leq K S 1_{\text {upper }, j}$

$K S 2_{0 j} \leq K S 2_{j} \leq K S 2_{\text {upper }, j}$

\section{Power transmission constraints}

$T p_{b, d, t}+T n_{b, d, t} \leq K T_{b}$

$K T_{0 b} \leq K T_{b} \leq K T_{\text {upper }, b}$

$K T_{0 b}=K T_{\text {upper }, b}=\frac{\pi}{6} \frac{1}{x_{b}}$

$T p_{b, d, t} \leq$ flow $_{b}$

$T n_{b, d, t} \leq$ flow $2_{b}$ 


\section{Capacity reserve constraints}

The following equation confirms required reserve capacity in a power system preparing for the risks of power supply shutdown:

\section{Charge and discharge balances of energy storage}

Charging and discharging behaviors of pumped-hydro and rechargeable battery are described in the following equations:

$\sum_{i \in I A_{a}} A p_{i, d}+\sum_{i \in I C_{a}} u_{i, d, t} \times K_{i}+\sum_{j \in J A_{a}} u s 1_{j, d} \times K S 1_{j} \geq(1+\delta) \times \max _{t \in T} \sum_{n \in N_{a}} l o a d_{n, d, t}$.

\section{Load following capability of power plants}

Following equations explain the capability of adjusting electric power output into incremental increase or decrease of electricity demand for power plants:

$P_{i, d, t}-\frac{1}{6}$ decrease $_{i} \times A p_{i, d} \leq P_{i, d, t+1} \leq P_{i, d, t}+\frac{1}{6}$ increase $_{i} \times A p_{i, d}$,

$$
\begin{aligned}
S S_{j, d, t+1}= & \left(1-\frac{1}{6} s d_{j}\right) \times S S_{j, d, t} \\
& +\frac{1}{6} \sqrt{e f f_{\text {storage }, j}} C h a_{j, d, t}-\frac{1}{6} \frac{1}{\sqrt{\text { eff }_{\text {storage }, j}}} \text { Dis }_{j, d, t}
\end{aligned}
$$

$P_{i, d, t}-\frac{1}{6}$ decrease $_{i} \times u_{i, d, t} \times K_{i} \leq P_{i, d, t+1} \leq P_{i, d, t}+\frac{1}{6}$ increase $_{i} \times u_{i, d, t} \times K_{i}$.

\section{Minimum output threshold of thermal power plant}

The following equation shows that thermal power plant operates more than a minimum threshold, excluding thermal plant with daily start and stop mode (DSS). For sharp demand variations within a day, thermal plant with DSS mode generates electricity under rapid heat-up and cooldown cycle. Elaborate explanations are available in Komiyama and Fujii (2014, 2017):

$P_{i, d, t} \geq\left(\operatorname{DMax}_{i, d}-d s s_{i} \times A p_{i, d}\right) \times \mathrm{mol}_{i}$

$\operatorname{DMax}_{i, d} \geq P_{i, d, t}$

$\operatorname{DMax}_{i, d} \geq P_{i, d+1, t}$

$$
K S 1_{j} \leq \text { crate }_{j} \times K S 2_{j}
$$

$$
\frac{1}{6} \sum_{d=0}^{D-1} \sum_{t=0}^{T-1} C h a_{j, d, t} \leq K S 2_{j} \times u s 2_{j, d} \times \frac{\text { cycle }_{j}}{\text { lifetime }_{j}} .
$$

\section{Renewable energy scenarios for offshore wind}

The Japan's official energy outlook assumes the appropriate fraction of renewable energy in the power generation mix as $22-24 \%$ in 2030 . However, Japan actually has abundant renewable resources, such as offshore wind

Table 2 Case setting for installed capacity of renewable energy in Japan

\begin{tabular}{lllll}
\hline & Base & $\begin{array}{l}\text { Renewable } \\
\text { expansion } \\
\text { (RE) }\end{array}$ & $\begin{array}{l}\text { RE with more PV and off- } \\
\text { shore wind (fixed-foundation) } \\
{[\text { REMx+OF] }}\end{array}$ & $\begin{array}{l}\text { RE with more PV and offshore } \\
\text { wind (fixed-found and floating) } \\
\text { [REMx+OFMx] }\end{array}$ \\
\hline Solar PV & $64 \mathrm{GW}$ & $128 \mathrm{GW}$ & $256 \mathrm{GW}$ & $256 \mathrm{GW}$ \\
Wind (onshore) & $10 \mathrm{GW}$ & $30 \mathrm{GW}$ & $30 \mathrm{GW}$ & $30 \mathrm{GW}$ \\
Wind (offshore, fixed-foundation) & $0 \mathrm{GW}$ & $0 \mathrm{GW}$ & $20 \mathrm{GW}$ & $20 \mathrm{GW}$ \\
Wind (offshore, floating) & $0 \mathrm{GW}$ & $0 \mathrm{GW}$ & $0 \mathrm{GW}$ & $13 \mathrm{GW}$ \\
Hydro & $24 \mathrm{GW}$ & $24 \mathrm{GW}$ & $24 \mathrm{GW}$ & $24 \mathrm{GW}$ \\
Geothermal & $1.7 \mathrm{GW}$ & $3.1 \mathrm{GW}$ & $3.1 \mathrm{GW}$ & $3.1 \mathrm{GW}$ \\
Biomass & $3.6 \mathrm{GW}$ & $5.5 \mathrm{GW}$ & $5.5 \mathrm{GW}$ & $5.5 \mathrm{GW}$ \\
\hline
\end{tabular}

REMx+OFMx assumes the maximum integration of variable renewable in Japan 
resource, to enhance renewables' fraction and holds more potential of decarbonizing the country's power supply. Therefore, particularly focusing on offshore wind, it is important to investigate optimal power generation mix under even more integration of renewable in the power system than that assumed in the official supply plan. Such simulation has an importance, because Japan aims to mitigate carbon emissions by $80 \%$ from the current level to 2050 (Prime Minister of Japan 2008) and elaborate effort for the power supply decarbonization by renewable is obviously an indispensable measure. According to the project of energy model intercomparison in Energy Modeling Forum (EMF) 35, the role of renewable energies is estimated to be enhanced in the Japanese power sector toward 2050 under $80 \%$ emission reduction scenario (Shiraki et al. 2020).

This manuscript aims to evaluate the impact of power grid integration of renewable resources including offshore wind power which is not elaborately considered so far in existing literatures and to assess the potential role of whole renewables in national power generation mix. This paper assumes four scenarios about renewable energy in Japan as assumed in Table 2. In each scenario, an optimal power generation mix is evaluated, employing the model developed here. Base case assumes the same capacity of renewable energy as described in the official power supply outlook (METI 2015), while a part of renewable expansion case (REMx+OF, REMx+OFMx) assumes the deployment of offshore wind power, together with the extensive deployment of PV and onshore wind. Regarding the target year of the analysis, the scenarios in Table 2 assume power generation mix in 2030, and Base case assumes the mix in 2030 based on the official outlook (METI 2015).

The capacity of renewable in Base case is assumed by reflecting the values in (METI 2015). In each case, PV and onshore wind capacities are exogenously allocated into each node of the model on the basis of those capacities registered in FIT system (METI 2016) and installable potential investigated by Ministry of Environment in Japan (MOE 2013). Concerning PV capacity, RE case assumes the double of that in Base case, and both $\mathrm{REMx}+\mathrm{OF}$ and REMx+OFMx cases set nearly the maximum potential of PV deployment in Japan as estimated in (MOE 2013) equivalent to four times of the Base case. About onshore wind, RE, REMx+OF and REMx+OFMx cases assume the maximum installable potential in Japan as well which amounts to $30 \mathrm{GW}$, triple as that in Base case. In both $\mathrm{REMx}+\mathrm{OF}$ and REMx+OFMx cases, offshore wind deployment is explicitly considered as shown in Fig. 9, according to the governmental assessment (MOE 2015), and Table 3 shows the regional offshore wind capacity in the both cases. According to the study (MOE 2015),

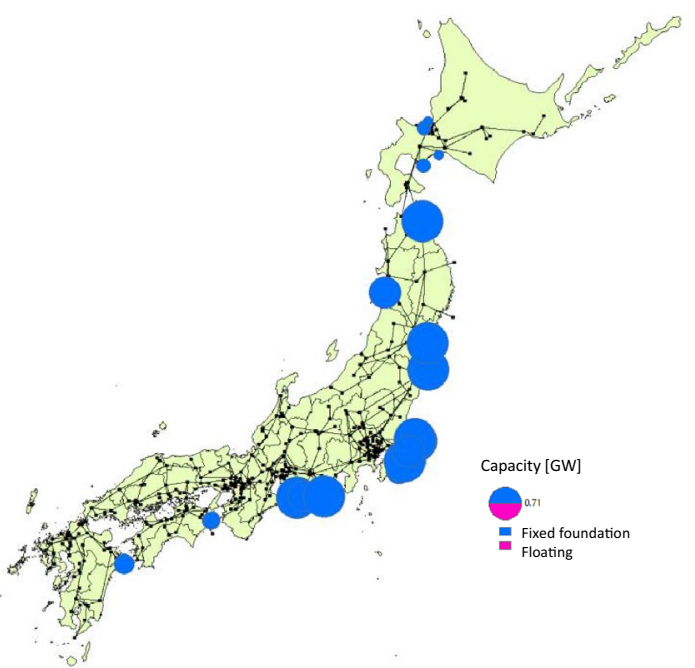

(a) $\mathrm{REMx}+\mathrm{OF}$ (Fixed foundation offshore wind)

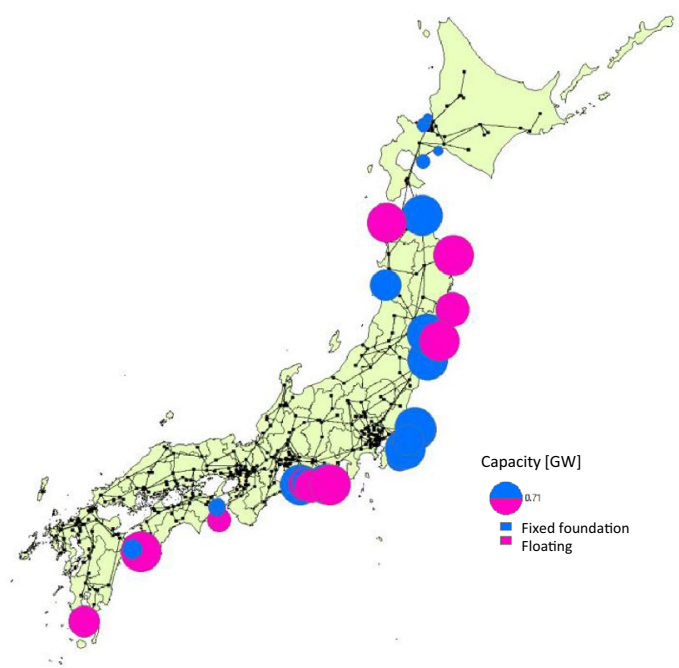

(b) REMx + OFMx (Fixed foundation \& Floating offshore wind)

Fig.9 Nodal distribution of offshore wind capacity in REMx+OF and $\mathrm{REMx}+\mathrm{OFMx}$

REMx+OF case assumes $20 \mathrm{GW}$ installation of fixed foundation offshore wind, while REMx+OFMx supposes furthermore $13 \mathrm{GW}$ deployment of floating offshore wind power.

\section{Optimal mix of power generation and capacity}

Figure 10 shows the configuration about power generation and capacity of Japan in individual scenario. As shown in Fig. 10a, the increased installation of renewable energy encourages fuel switching from thermal power generation 
Table 3 Regional offshore wind capacity in $\mathrm{REMx}+\mathrm{OF}$ and $\mathrm{REMx}+\mathrm{OFMx}$ cases

\begin{tabular}{llllll}
\hline GW & \multicolumn{2}{l}{ REMx+OF } & & \multicolumn{2}{l}{ REMx+OFMx } \\
\cline { 2 - 3 } \cline { 5 - 6 } & $\begin{array}{l}\text { Fixed-foun- } \\
\text { dation }\end{array}$ & Floating & & $\begin{array}{l}\text { Fixed-foun- } \\
\text { dation }\end{array}$ & Floating \\
\hline Hokkaido & 0.7 & 0 & 0.7 & 0 \\
Tohoku & 7.1 & 0 & 7.1 & 6.2 \\
Kanto & 6.8 & 0 & & 6.8 & 0 \\
Chubu & 4.3 & 0 & & 4.3 & 3.9 \\
Hokuriku & 0 & 0 & 0 & 0 \\
Kansai & 0 & 0 & 0 & 0 \\
Shikoku & 0.5 & 0 & & 0.5 & 2.3 \\
Chugoku & 0 & 0 & & 0 & 0 \\
Kyushu & 0.4 & 0 & 0.4 & 1.0 \\
Total & 19.7 & 0 & 19.7 & 13.4 \\
\hline
\end{tabular}

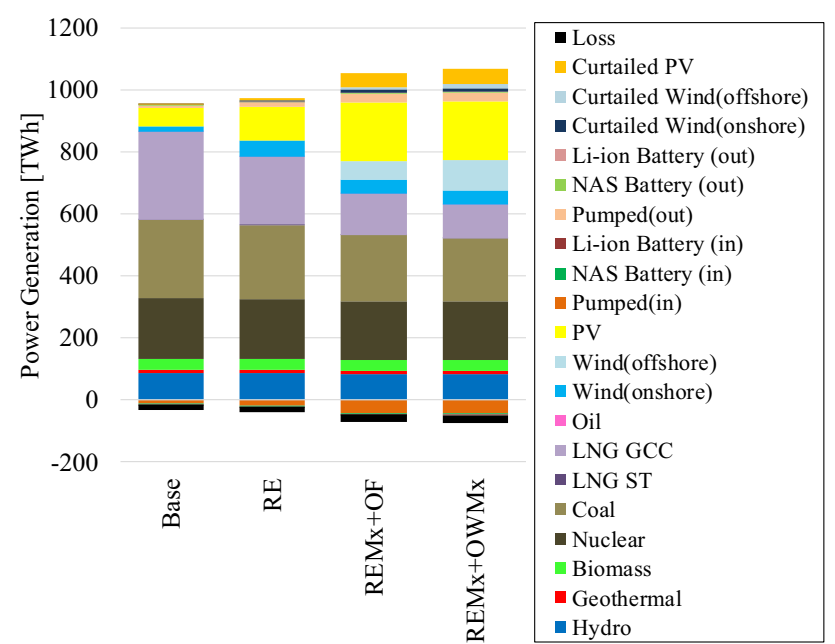

(a) Power generation

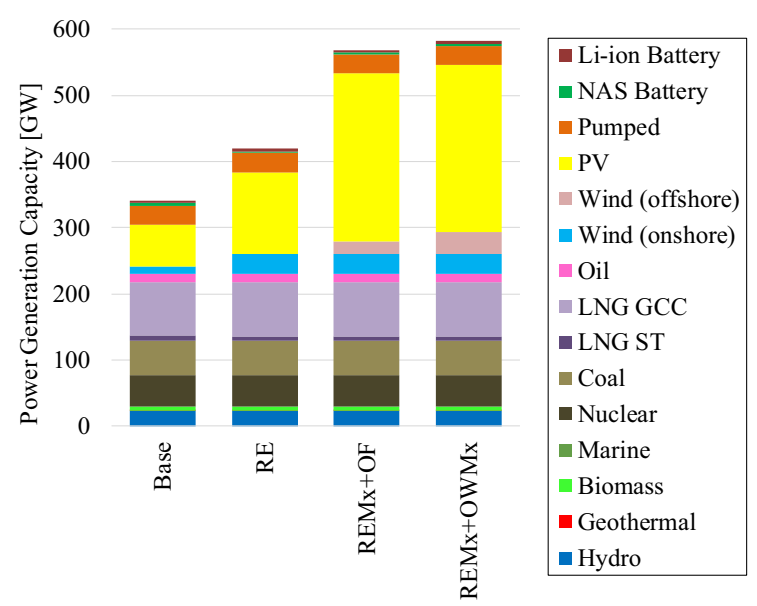

(b) Capacity

Fig.10 Power generation and capacity of each technology in Japan, calculated under multiple renewable energy scenarios

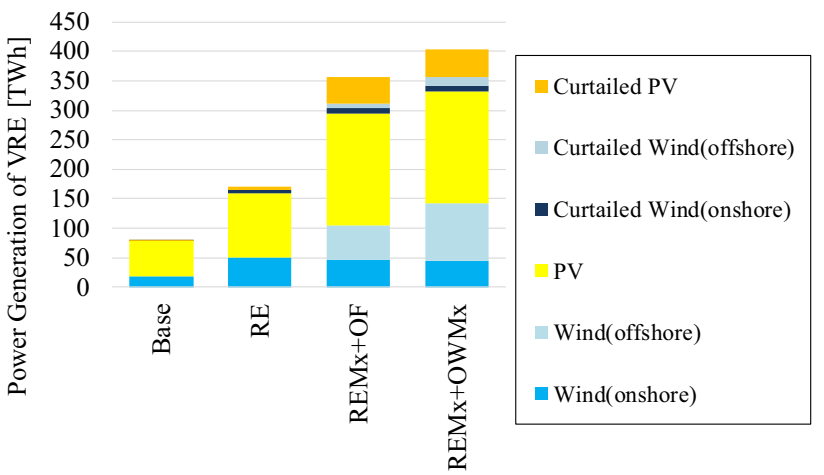

Fig.11 Power generation by variable renewable energy in Japan, calculated under multiple renewable energy scenarios

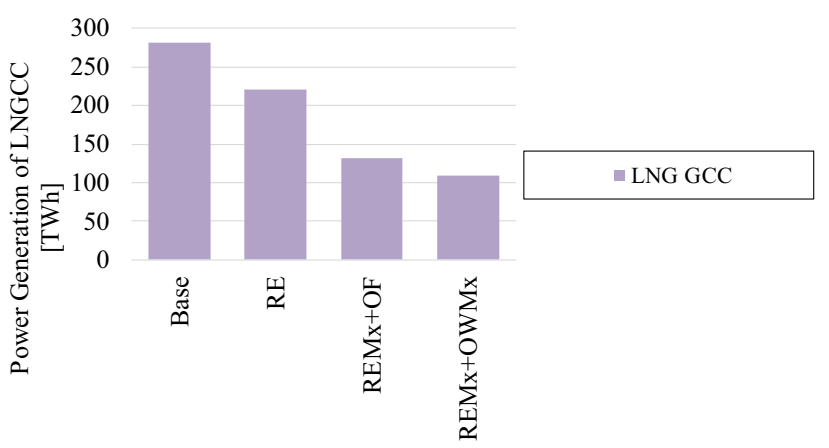

Fig.12 LNGCC power generation in Japan, calculated under multiple renewable energy scenarios

in $\mathrm{RE}, \mathrm{REM} x+\mathrm{OF}$ and $\mathrm{REM} x+\mathrm{OFMx}$ cases. In REMx+OF case, the fraction of variable renewable energy (VRE) such as onshore wind, offshore wind and solar PV accounts for $30 \%$ of total annual power generation. Since the fraction of VRE in the Japanese power generation mix in 2017 is still 5.8\% (Solar PV: $5.2 \%$, Wind: 0.6\%), the simulation result in $\mathrm{REMx}+\mathrm{OF}$ suggests that the power system requires more measures for the variability of VRE to ensure power supply security and adequacy. In REMx+OFMx, furthermore, the fraction of VRE dominates $33 \%$ of the total power generation. Renewable energy resources as a whole, consisting of those VREs and other renewables, achieve almost $50 \%$ in total annual power supply. If nuclear included, the ratio of zero emission power resource achieves $70 \%$ of total power supply in this case.

Between RE and REMx+OF in Fig. 10b and Table 2, PV capacity and offshore wind capacity increase by $128 \mathrm{GW}$ and $20 \mathrm{GW}$, respectively, and the growth of PV capacity amounts to more than 6 times of that of offshore wind capacity. In terms of energy (GWh) basis in Fig. 10a, however, PV output and offshore wind output increase by $81 \mathrm{TWh}$ and $58 \mathrm{TWh}$ individually, and the growth of PV output shows only 1.4 time of that of offshore wind output in spite of 6 


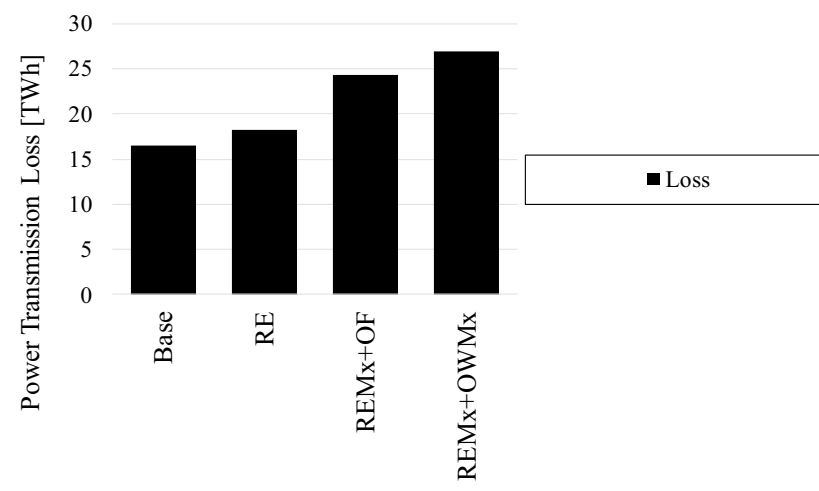

Fig.13 Power transmission loss in Japan, calculated under multiple renewable energy scenarios

Table 4 Carbon emissions and carbon intensity of electricity in each scenario

\begin{tabular}{lll}
\hline & $\begin{array}{ll}\mathrm{CO}_{2} \text { emissions [Mt- } \\
\left.\mathrm{CO}_{2}\right]\end{array}$ & $\begin{array}{l}\text { Carbon intensity } \\
{\left[\mathrm{kg}-\mathrm{CO}_{2} / \mathrm{kWh}\right]}\end{array}$ \\
\hline Base & 301 & 0.327 \\
RE & 267 & 0.287 \\
REMx + OF & 215 & 0.219 \\
REMx + OFMx & 200 & 0.202 \\
\hline
\end{tabular}

times capacity growth of PV over offshore wind. From the viewpoint of the investment for enhancing renewable energy, offshore wind has larger advantage over solar PV in terms of obtained power output per unit capacity.

As VRE penetrates more in the power grid, output curtailment of renewable increases as described in Fig. 11 and this might harm the economics of VRE. In REMx+OFMx, for instance, the ratio of annual output curtailment over total annual power generation in solar PV amounts to $20 \%$, and it implies that the utilization efficiency of PV output drops in spite of its massive integration to the power grid. It should be noted, however, that the curtailment of renewable energy in this model depends on multiple factors such as installed PV capacity, installed energy storage facility and power transmission capacity. In this case, according to Fig. 12, LNGCC power generation declines largely by two-third compared with that in Base case, due to increased renewable penetration, because LNG import price is relatively expensive in Japan and VRE with zero marginal cost replaces LNG power generation first and foremost. Figure 13 shows that total power transmission loss of Japan. The loss in REMx+OFMx will be increased by 10 billion $\mathrm{kWh}$ from the level of Base case, because the variability of increased VRE including offshore wind is required to be controlled by more nationwide flexible power resources such as thermal power plants and electricity storage. As for the installation of stationary rechargeable battery such as NAS and Li-ion batteries, it is not so much observed in this paper, because rechargeable battery is less economically favorable due to its higher cost and other more affordable flexible sources such as LNGCC mainly controls VRE outputs. In this paper, the costs of NAS battery and Li-ion battery are assumed as $200 \$ / \mathrm{kWh}$ and $400 \$ / \mathrm{kWh}$, respectively (Komiyama and Fujii 2019), and it should be noted that the battery installation could be changed if the model assumes much lower cost.

Concerning environmental aspects, Table 4 shows carbon emissions and carbon intensity of electricity in each scenario. As renewable sources are more integrated from Base case to REMx+OFMx case, carbon intensity is observed to be significantly reduced from the level of Base case. Currently, the official target of the carbon intensity of electricity in 2030 is $0.370 \mathrm{~kg}-\mathrm{CO}_{2} / \mathrm{kWh}$ (METI 2017). In REMx+OFMx case which assumes the large-scale integration of renewable in 2030, the carbon intensity is dramatically reduced to $0.202 \mathrm{~kg}-\mathrm{CO}_{2} / \mathrm{kWh}$ that is almost halved of the official target. This implies that more decarbonization of electricity than the official target could be potentially feasible by the extensive integration of renewables by 2030 .

\section{Power system integration of variable renewable}

Monthly optimal dispatch of power generators of Japan in January is illustrated in Fig. 14. The figure includes the result in the four renewable scenarios. According to the figures, VRE variability is controlled with rechargeable battery, pumped-hydro, flexible operation by LNGCC and coal-fired generators, and VRE output curtailment. Thus, it is important to recognize that, compared with conventional power dispatch only through peak, middle and baseload generators, extensive VRE integration causes a significant transformation in a power system operation. In $\mathrm{REMx}+\mathrm{OF}$ and REMx+OFMx, large-scale VRE output curtailment is observed to serve as an economical option to reduce its excessive output, rather than charging all surplus VRE output to rechargeable battery which is a relatively expensive technical option compared with flexible operation of thermal and pumped-hydro. In the same cases, the figure implies that offshore wind power, which has higher capacity factor, largely reduce the dependence on the role of thermal power generation such as LNGCC.

\section{Impact on wholesale price in electricity market}

As mentioned in the introduction, in Kyushu electric power company, wholesale price remains zero when PV output increases in daytime, as depicted in Fig. 15. The wholesale 


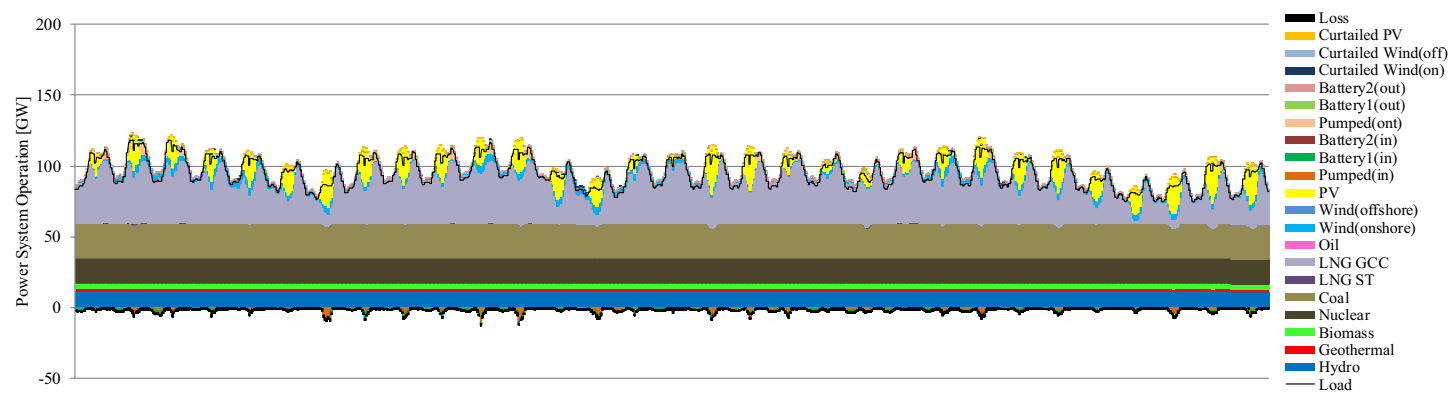

(a) Base

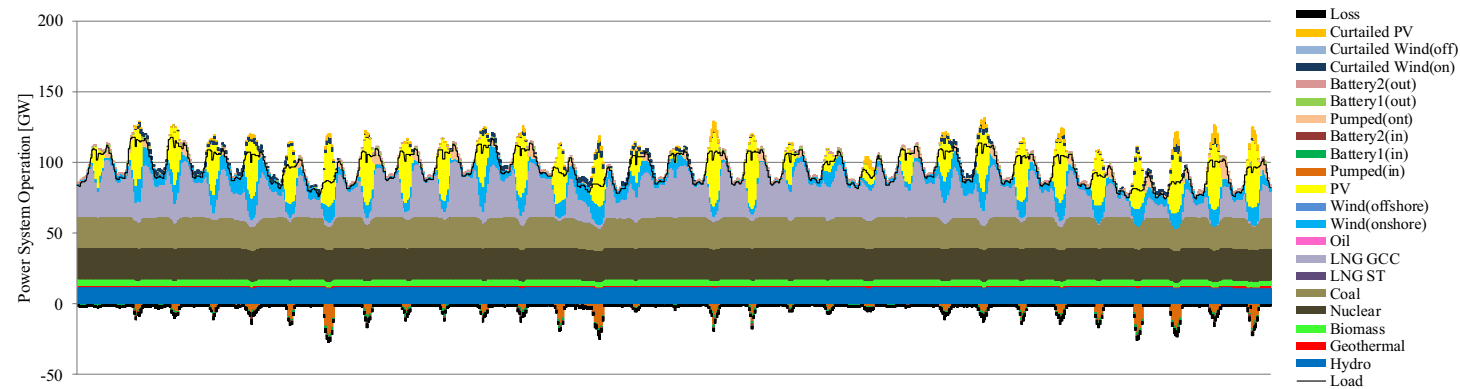

(b) RE

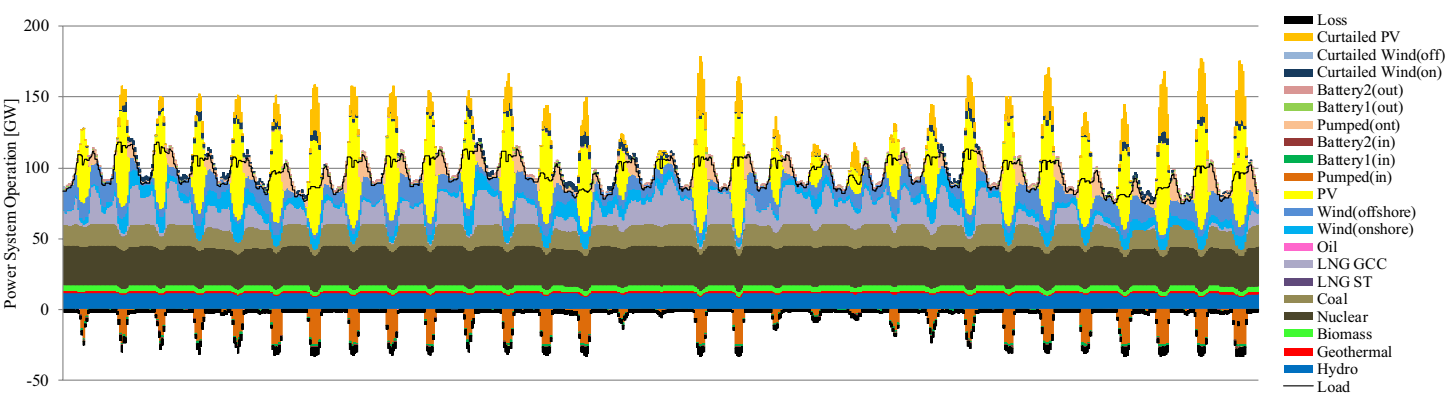

(c) $\mathrm{REMx}+\mathrm{OF}$

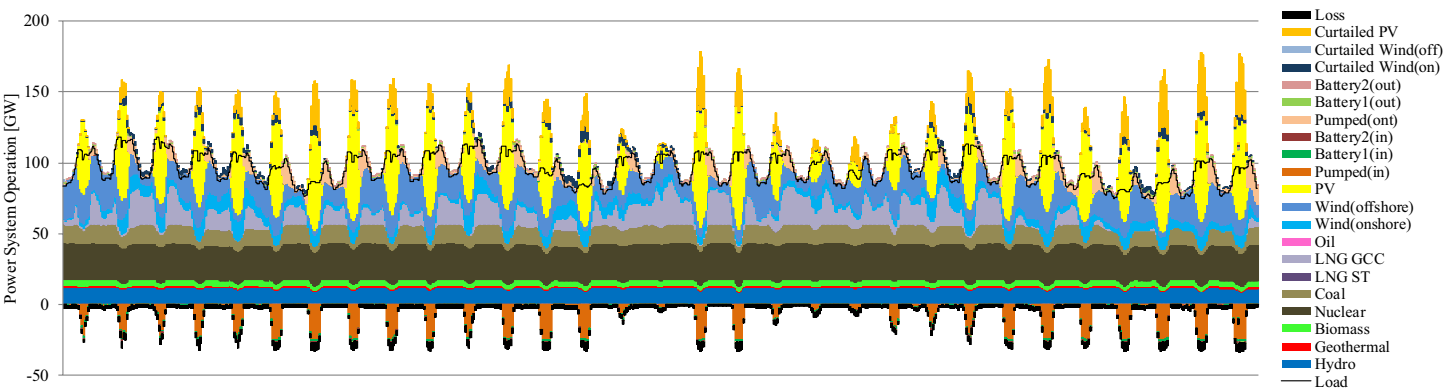

(d) $\mathrm{REMx}+\mathrm{OFMx}$

Fig.14 Monthly dispatch in January for multiple renewable scenarios in Japan. The horizontal axis shows the time from January 1st to January 31th in hourly temporal resolution

price is derived from (JEPX 2020). In case of wind power, its capital cost is higher while the variable cost is almost zero. Therefore, extensive wind power integration might suppresses the level of wholesale prices by eliminating higher fuel-cost thermal units in wholesale market. This downslide of wholesale prices triggered by VRE, however, might reduce the market income of thermal or nuclear power generator, called as dispatchable generator. This market 
Fig.15 Electricity dispatch and wholesale power price in Kyushu area in May 3, 2019, compiled from Kyushu Electric Power Transmission and Distribution (2020)
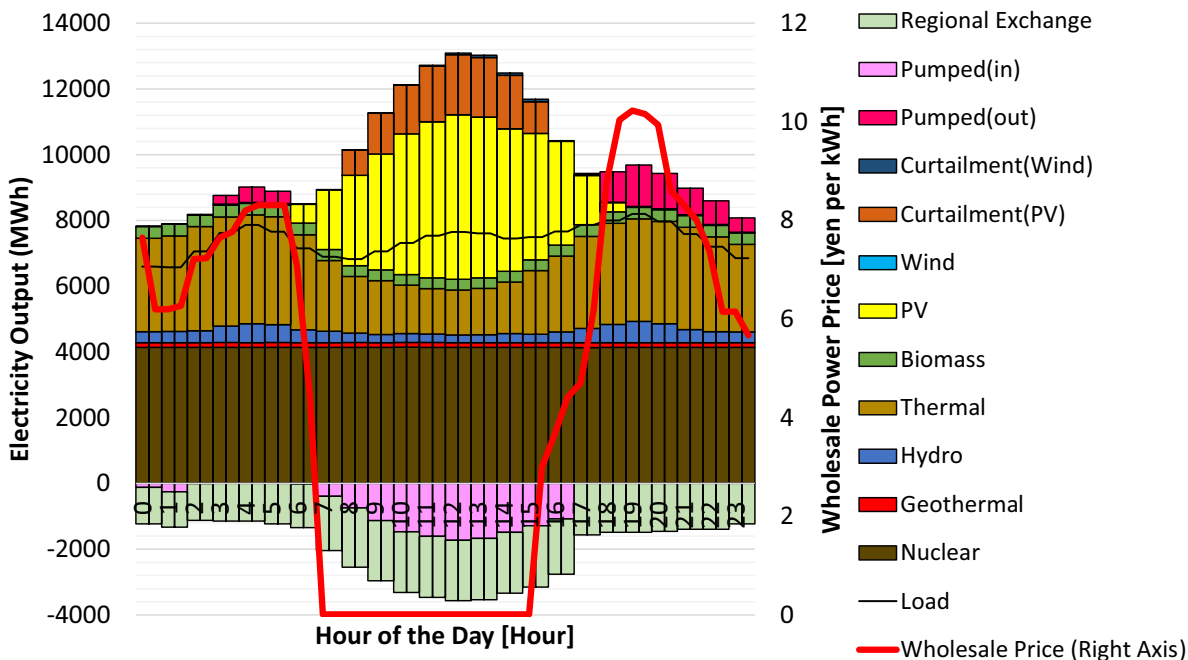

phenomena caused by VRE is called as a missing money problem (Hogan 2017). A fall in monetary gain from the market might induce dispatchable generators to phase out from a power system and eventually make it difficult to maintain a required power supply adequacy of the market. Until now, utility companies has planned to phase out old thermal power generators, raising a concern for mid-term sufficient power supply capability (OCCTO 2018). Hence, important agenda in the Japanese power system is considered to be simultaneous achievement of both sufficient electricity supply capacity and extensive VRE integration in the power system.

Against those background, this manuscript attempt to assess the possible impact of VRE integration including offshore wind on the trend of wholesale power prices. Figure 16 shows the yearly average of locational marginal electricity price (LMP) in respective 383 buses on Base and REMx+OFMx cases. The model developed here can yield wholesale power price information by calculating the shadow price of nodal electricity demand, that is, by estimating the shadow price of Eq. (3). According to Fig. 16a, even in Base case, relatively lower wholesale price is observed in Hokkaido, Tohoku and Kyushu area due to higher VRE penetration over power demand in those areas, while relatively higher price is observed in demand-intensive area such as Tokyo area. LMP is thus considered to be useful index for representing electricity imbalance in individual node caused by VRE. As implied by Fig. 16b, massive renewable integration in REMx+OFMx suppresses LMP in the whole power grid. In this case, VRE marginal price which is equivalent to zero becomes dominant in electricity supply curve during the period of intensive VRE output, and the wholesale price tends to be even lower than that in $\mathrm{REMx}+\mathrm{OF}$ case. In addition, in REMx+OFMx case, large-scale renewable resources are integrated nationwide in Japan, and total power supply capacity in each service area significantly outstrips the power demand. As a result, the wholesale prices go down in a country as a whole, and nodal gap of annual average wholesale price becomes smaller.

Figure 17 shows wholesale price curve in Tohoku region where large-scale offshore wind is integrated. This paper assesses the impact of renewable energy integration including offshore wind on the movement of wholesale electricity price. The figure shows the annual movement of wholesale price in a descending order. In Tohoku region where the resource endowment of wind and PV are abundant compared with the electricity demand, wholesale electricity price drops and collapses to almost zero in REMx+OFMx during one-third of $8760 \mathrm{~h}$ per year. Therefore, extensive VRE integration with offshore wind is supposed to affect the profitability of dispatchable generators through the collapse of wholesale price.

\section{Economical feasibility of power grid expansion}

Capacity expansion of power transmission lines is necessary for connecting large-scale VRE into a power grid and for ensuring access route to system resources controlling VRE output. However, the reinforcement of power grid capacity is expensive in general, and should be implemented in consideration of its cost effectiveness.

To quantify the economical feasibility of power grid extension, shadow prices with regard to capacity expansion for 441 bulk power transmission lines are calculated and illustrated in Fig. 18 for REMx+OFMx scenario. The shadow price here is a convenient index representing total power system cost reduction through expanding the capacity of bulk transmission line. The price level corresponds to the magnitude of total system cost reduction by grid expansion. Based on the figure, the increasing capacities of 


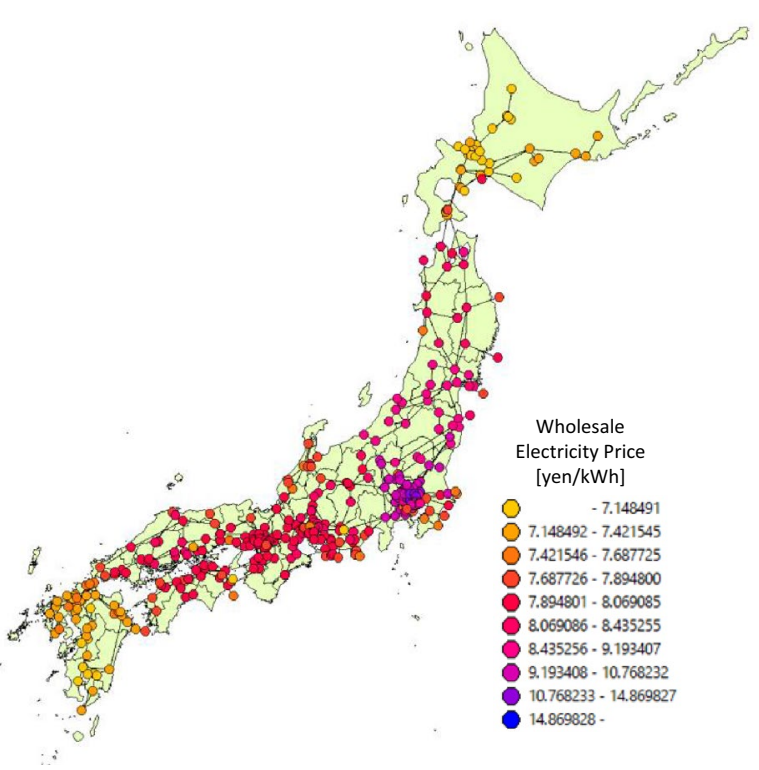

(a) Base

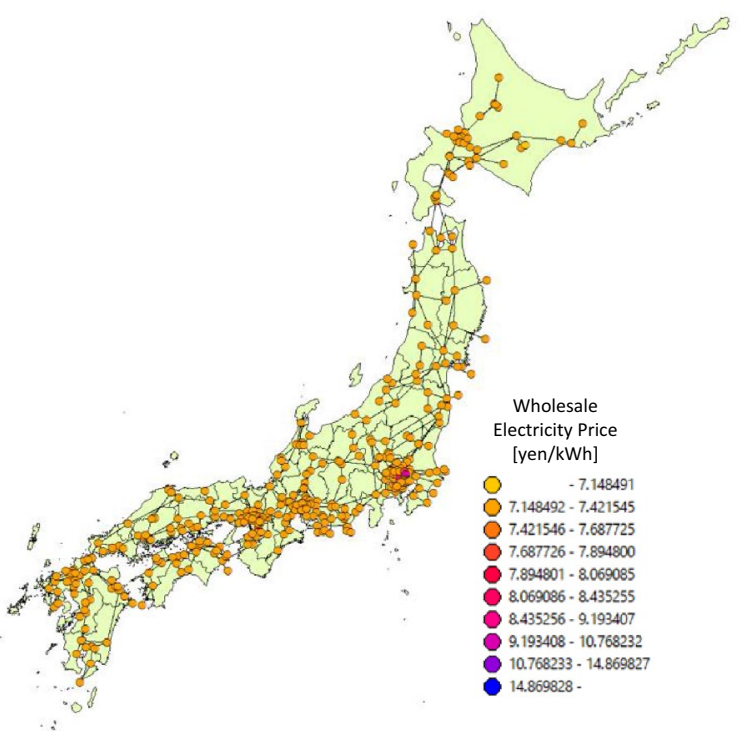

(b) REMx + OFMx (Fixed foundation \& Floating)

Fig.16 Locational marginal electricity price (LMP) of 383 nodes, calculated under multiple renewable energy scenarios

specific bulk power transmission lines, such as a regional transmission line between Hokkaido and mainland Japan, are beneficial to further reduce total system cost under massive VRE penetration. The reason is because the relaxation of power transmission bottleneck contributes, first, to integrate more renewable with lower marginal cost to suppress total system cost and, secondly, to access more economical dispatchable resources for controlling output variability of VRE. Figure 18, therefore, plays an important role to discuss the economical validity of power transmission expansion.

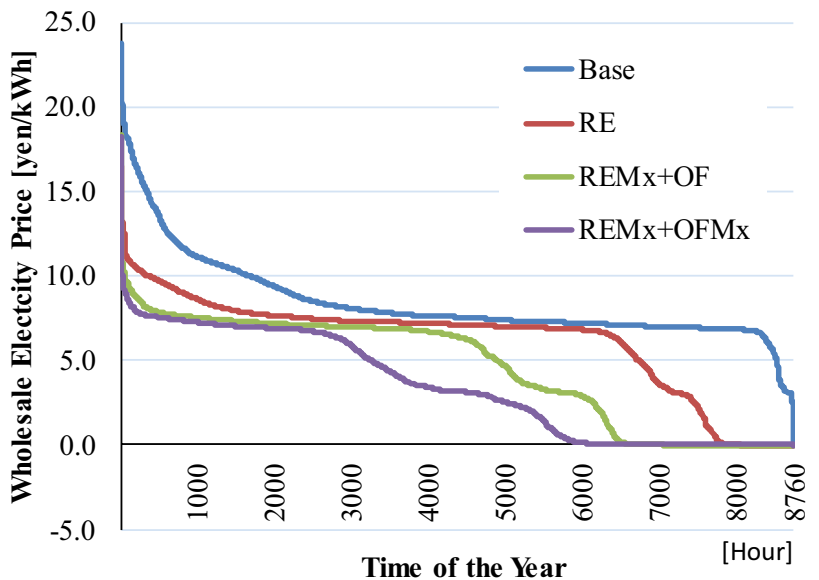

Fig.17 Wholesale price curve in Tohoku region, calculated under multiple renewable energy scenarios. Wholesale price is evaluated through the average of LMP among the nodes belonging to the region

Other than the line between Hokkaido and mainland Japan, Fig. 18 reveals that the extension of inter-regional power transmission line contributes to reduce power system cost potentially such as the line between Tohoku and Kanto, between Kanto and Chubu and between Shikoku and mainland Japan. The figure suggests that the reinforcement of inter-regional line is important under massive renewable integration, because electric power flow goes back and forth between regions due to the widespread penetration of renewable energy in Japan.

\section{Conclusions and implications}

Although Japan has the immense installable potential of offshore wind power, its power grid integration is not fully analyzed so far. This paper evaluates an optimal power generation mix of Japan in 2030 by considering the potential expansion of renewables including offshore wind deployment with an electric power system model; the highlight of the model consists in the topology of a power grid including 383 buses and 472 lines in an hourly resolution per year.

The Japanese electricity sector becomes increasingly interested in offshore wind power resources, because Japan has a $1600 \mathrm{GW}$ of offshore wind potential in contrast with $300 \mathrm{GW}$ of onshore wind. However, the seacoast geography with deep ocean close to its coast causes significant restriction of offshore wind availability in Japan. Therefore, for integrating offshore wind into the grid, power system planning should consider both the location of available offshore wind resource and the constraint of power grid capacity. This paper analyzes an optimal power generation mix integrated with an extensive amount of renewable energy by 


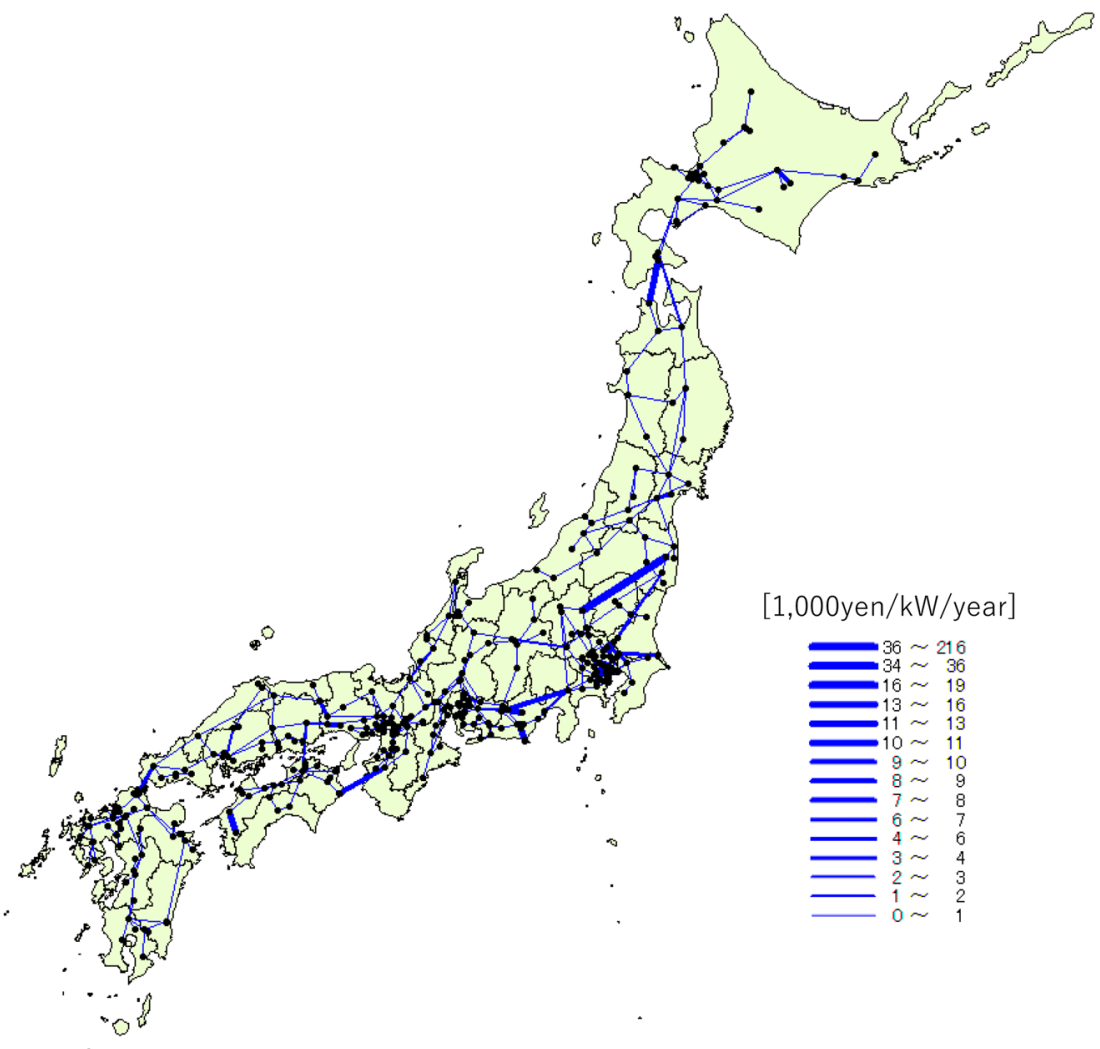

(a) National view of power transmission network
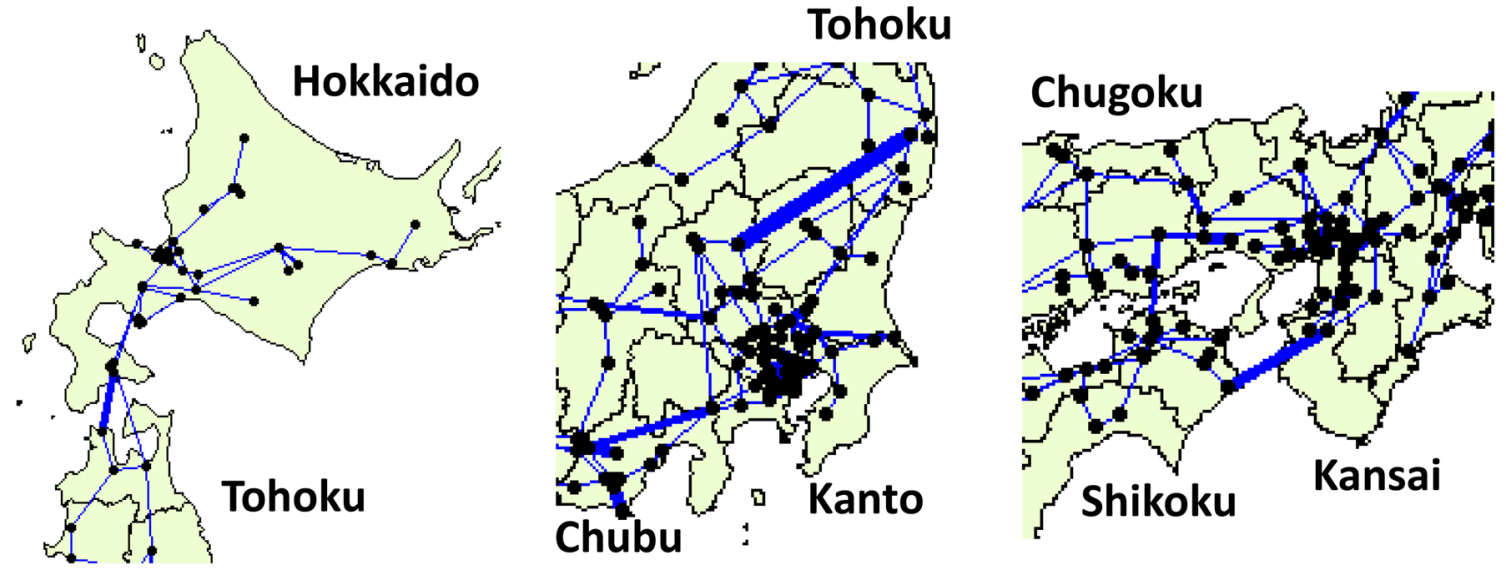

(b) Regional view of power transmission network

Fig.18 Shadow price for the capacity of bulk power transmission line in REMx-OFMx scenario. The shadow price corresponds to the value of total system cost reduction by the expansion of unit capacity of power transmission line

considering the detailed location of offshore wind resource and the detailed topology of power grid.

In the case integrating massive offshore wind based on official resource assessment like REMx+OFMx case of this study, the fraction of VRE including onshore and offshore winds with solar PV accounts for $33 \%$ of total annual power supply. Renewable resources as a whole, consisting of those VREs and other renewables, achieve almost $50 \%$ in total annual power generation, and the calculated results imply that $33 \mathrm{GW}$ of offshore wind, including $20 \mathrm{GW}$ of fixed 
foundation and $13 \mathrm{GW}$ of floating offshore wind, could contribute to achieve $50 \%$ of renewable penetration in the power generation mix of Japan. If nuclear considered, zero emission power sources account for $70 \%$ of total annual power supply, and this provides the technically feasible pathway of the Japanese power sector to massively decarbonizing its electricity supply.

As implied in the simulated results of wholesale price, on the other hand, extensive VRE integration might cause wholesale power price collapse and eventually encompass income decrease in dispatchable generators such as thermal units. This raises concerns for ensuring enough supply reliability of power system by failing incentives for the sufficient investment of dispatchable units. One of the challenges to be addressed in the electricity market policy is, hence, to reform electricity market for simultaneously accomplishing both large-scale VRE integration and sufficient power supply securement. In Japan, policy designs are under discussion for alternative income opportunity such as capacity market and real-time market, and those markets are expected to underpin the monetary revenue of dispatchable generators other than wholesale market. According to the policy direction shown in the electricity market institution of Japan (METI 2018b), the government plans to establish capacity market, which pays reward for the capacity value of power generator and assigns that reward directly on electricity consumer, and real-time market, which pays reward as well for the ramp capability of power generator and assigns the reward on final consumer through transmission tariff. Those markets are of crucial importance to guarantee adequate monetary gain for dispatchable units and eventually to keep power supply adequacy under extensive VRE penetration. On the other hand, electricity consumer would have both positive and negative impacts. As a positive impact, consumer will benefit from lower wholesale price, while consumer will have a risk of paying more transmission tariff caused by reinforcing power grid through extensive renewable energy integration. The total net impact is considered to be a future important research agenda.

Future study is to consider electricity saving and extension mechanisms such as battery control in electric vehicle and output control of small-scale combined heat and power plant such as cogeneration system (CGS).

Acknowledgements This research was financially supported by JSPS KAKENHI Grant Number JP20H02679 and JP17H03531, and by the Environment Research and Technology Development Fund 2-1704 of the Environmental Restoration and Conservation Agency.

Open Access This article is licensed under a Creative Commons Attribution 4.0 International License, which permits use, sharing, adaptation, distribution and reproduction in any medium or format, as long as you give appropriate credit to the original author(s) and the source, provide a link to the Creative Commons licence, and indicate if changes were made. The images or other third party material in this article are included in the article's Creative Commons licence, unless indicated otherwise in a credit line to the material. If material is not included in the article's Creative Commons licence and your intended use is not permitted by statutory regulation or exceeds the permitted use, you will need to obtain permission directly from the copyright holder. To view a copy of this licence, visit http://creativecommons.org/licenses/by/4.0/.

\section{References}

Becker S, Frew BA, Andresen GB, Zeyer T, Schramm S, Greiner M, Jacobson MZ (2014) Features of a fully renewable US electricity system: optimized mixes of wind and solar PV and transmission grid extensions. Energy 72:443-458. https://doi.org/10.1016/j. energy.2014.05.067

Budischak C, Sewell D, Thomson H, Mach L, Veron DE, Kempton W (2013) Cost-minimized combinations of wind power, solar power and electrochemical storage, powering the grid up to $99.9 \%$ of the time. J Power Sources 225:60-74. https://doi.org/10.1016/j.jpows our.2012.09.054

Dietrich K, Latorre JM, Olmos L, Ramos A (2012) Demand response in an isolated system with high wind integration. IEEE Trans Power Syst 27(1):20-29. https://doi.org/10.1109/TPWRS.2011. 2159252

Elliston B, Diesendorf M, MacGill I (2012) Simulations of scenarios with $100 \%$ renewable electricity in the Australian national electricity market. Energy Policy 45:606-613. https://doi.org/10. 1016/j.enpol.2012.03.011

Hart EK, Jacobson MZ (2011) A Monte Carlo approach to generator portfolio planning and carbon emissions assessments of systems with large penetrations of variable renewables. Renew Energy 36(8):2278-2286. https://doi.org/10.1016/j.renene.2011.01.015

He G, Avrin AP, Nelson JH, Johnston J, Mileva A, Tian J, Kammen DM (2016) SWITCH-China: a systems approach to decarbonizing China's power system. Environ Sci Technol 50(11):5467-5473. https://doi.org/10.1021/acs.est.6b01345

Hitaj C (2015) Location matters: the impact of renewable power on transmission congestion and emissions. Energy Policy 86:1-16. https://doi.org/10.1016/j.enpol.2015.06.019

Hogan M (2017) Follow the missing money: ensuring reliability at least cost to consumers in the transition to a low-carbon power system. Electricity J 30(1):55-61. https://doi.org/10.1016/j.tej. 2016.12.006

Institute of Electrical Engineers of Japan (IEEJ) (2004) Standard model of power grid of Japan, in Japanese. http://www2.iee.or.jp/ver2/ pes/23-st_model/index020.html. Accessed 23 April 2018

International Energy Agency (IEA) (2014) The power of transformation-wind, sun and the economics of flexible power systems. OECD, Paris, France. http://www.iea.org/bookshop/465-The Power_of_Transformation. Accessed 5 March 2018

Japan Electric Power Exchange (JEPX) (2020) Trading information http://www.jepx.org/english/market/index.html. Accessed 5 January 2020

Japan Meteorological Agency (JMA) (2007) Automated meteorological data acquisition system (AMeDAS), in Japanese.

Japan Wind Power Association (JWPA) (2017) Offshore wind power development in Japan. http://jwpa.jp/pdf/20170302_OffshoreWi ndPower_inJapan_forTWTIA.pdf. Accessed 15 January 2020

Komiyama R, Fujii Y (2014) Assessment of massive integration of photovoltaic system considering rechargeable battery in Japan with high time-resolution optimal power generation mix model. Energy Policy 66:73-89. https://doi.org/10.1016/j.enpol.2013. 11.022 
Komiyama R, Fujii Y (2017) Assessment of post-Fukushima renewable energy policy in Japan's nation-wide power grid. Energy Policy 101:594-611. https://doi.org/10.1016/j.enpol.2016.11.006

Komiyama R, Fujii Y (2019) Optimal integration assessment of solar PV in Japan's electric power grid. Renew Energy 139:1012-1028. https://doi.org/10.1016/j.renene.2019.02.130

Kyushu Electric Power Transmission and Distribution Co., Inc. (2020) Disclosure of power system information, in Japanese. https:// www.kyuden.co.jp/td_service_wheeling_rule-document_discl osure.html. Accessed 10 May 2020

Mai T, Mulcahy D, Hand MM, Baldwin SF (2014) Envisioning a renewable electricity future for the United States. Energy 65:374386. https://doi.org/10.1016/j.energy.2013.11.029

Marzooghi H, Verbič G, Hill DJ (2016) Aggregated demand response modelling for future grid scenarios. Sustain Energy Grids Netw 5:94-104. https://doi.org/10.1016/j.segan.2015.11.005

Ministry of Economy, Trading and Industry, Japan (METI) (2015) Long-term energy demand and supply outlook of Japan, in Japanese. http://www.meti.go.jp/press/2015/07/20150716004/20150 716004_2.pdf. Accessed 6 February 2020

METI (Ministry of Economy, Trade and Industry) (2016) Current status of renewable energy installation and the review on feedin-tariff system, in Japanese http://www.meti.go.jp/committee/ chotatsu_kakaku/pdf/020_01_00.pdf. Accessed 6 February 2020

METI (Ministry of Economy, Trade and Industry) (2017) Section 3 new mechanism in electric power system-innovation in the electric power system, Energy White Paper 2016, in Japanese https:// www.enecho.meti.go.jp/about/whitepaper/2016html/1-3-3.html. Accessed 1 December 2020

Ministry of Economy, Trading and Industry, Japan (METI) (2018a) The bill on promotion of territorial waters utilization for offshore renewable energy facilities, in Japanese. https://www.enecho.meti. go.jp/category/saving_and_new/saiene/yojo_furyoku/dl/legal/kaiyou_law.pdf. Accessed 6 February 2020

Ministry of Economy, Trading and Industry, Japan (METI) (2018b) Interim summary of issues about electricity market policy, in Japanese. http://www.meti.go.jp/committee/sougouenergy/denry oku_gas/denryoku_gas_kihon/seido_kento/pdf/20171226_01.pdf. Accessed 18 March 2019

Ministry of Economy, Trading and Industry, Japan (METI), Ministry of Land, Infrastructure, Transport and Tourism (MLIT) (2018) Arrangement of points for policy implementation towards renewable energy utilization in ocean area. https://www.meti.go.jp/shing ikai/enecho/denryoku_gas/saisei_kano/yojo_furyoku/pdf/001_ 03_00.pdf. Accessed 6 February 2020

METI (Ministry of Economy, Trade and Industry) (2019) Current status of renewable energy installation and the points arrangement in feed-in-tariff committee, in Japanese. https://www.meti.go.jp/ shingikai/santeii/pdf/046_01_00.pdf. Accessed 6 February 2020

Ministry of Economy, Trading and Industry, Japan (METI) (2020) Purchasing price and interval in Feed-in-tariff (FIT), in Japanese. https://www.enecho.meti.go.jp/category/saving_and_new/saiene/ kaitori/fit_kakaku.html. Accessed 19 March 2020

Ministry of Environment, Japan (MOE) (2011) Report of renewable energy installation potential in Japanese. https://www.env.go.jp/ earth/report/h23-03/. Accessed 13 March 2020
Ministry of Environment, Japan (MOE) (2013) Study of basic zoning information concerning renewable energies, in Japanese. http:// www.env.go.jp/earth/report/h25-03/full.pdf. Accessed 6 February 2020

Ministry of Environment, Japan (MOE) (2015) Report of power grid reinforcement for renewable energy installation, in Japanese. https://www.env.go.jp/earth/report/h27-02/index.html. Accessed 23 September 2019

Mizuno E (2014) Overview of wind energy policy and development in Japan. Renew Sustain Energy Rev 40:999-1018. https://doi.org/ 10.1016/j.rser.2014.07.184

National Renewable Energy Laboratory (NREL) (2014) Western wind and solar integration study. https://www.nrel.gov/docs/fy10osti/ 47434.pdf. Accessed 6 February 2020

New Energy and Industrial Technology Development Organization (NEDO) (2009) Report of feasibility study on offshore wind power.

Organization for Cross-regional Coordination of Transmission Operators (OCCTO) (2015) Summary of power supply plan in fiscal year 2015, in Japanese

Organization for Cross-regional Coordination of Transmission Operators (OCCTO) (2018) Summary of power supply plan in fiscal year 2018 in Japanese. https://www.occto.or.jp/kyoukei/torim atome/files/180330_kyoukei_torimatome.pdf. Accessed 30 May 2019

Prime Minister of Japan and His Cabinet (2008) In pursuit of "Japan as a Low-carbon Society" Speech by H.E. Mr Yasuo Fukuda, Prime Minister at the Japan Press Club. http://japan.kantei.go.jp/hukud aspeech/2008/06/09speech_e.html. Accessed 16 January 2010

Renewables.ninja (2019) https://www.renewables.ninja/. Accessed 11 January 2020

Riaz S, Marzooghi H, Verbič G, Chapman AC, Hill DJ (2019) Generic demand model considering the impact of prosumers for future grid scenario analysis. IEEE Trans Smart Grid 10(1):819-829. https:// doi.org/10.1109/TSG.2017.2752712

Schaber K, Steinke F, Hamacher T (2012) Transmission grid extensions for the integration of variable renewable energies in Europe: who benefits where? Energy Policy 43:123-135. https://doi.org/ 10.1016/j.enpol.2011.12.040

Shiraki H, Sugiyama M, Matsuo Y, Komiyama R, Fujimori S, Kato E, Oshiro K, Silva DH (2021) The role of renewables in the Japanese power sector: implications from the EMF35 JMIP. Sustain Sci (Accepted)

Sun M, Cremer J, Strbac G (2018) A novel data-driven scenario generation framework for transmission expansion planning with high renewable energy penetration. Appl Energy 228:546-555. https:// doi.org/10.1016/j.apenergy.2018.06.095

Tuohy A, Meibom P, Denny E, O'Malley M (2009) Unit commitment for systems with significant wind penetration. IEEE Trans Power Syst 24:592-601. https://doi.org/10.1109/TPWRS.2009.2016470

Publisher's Note Springer Nature remains neutral with regard to jurisdictional claims in published maps and institutional affiliations. 